\title{
Synchronizing Retinal Activity in Both Eyes Disrupts Binocular Map Development in the Optic Tectum
}

\author{
Stephen G. Brickley, ${ }^{1}$ Elizabeth A. Dawes, ${ }^{1}$ Michael J. Keating, ${ }^{1}$ and Simon Grant ${ }^{1,2}$ \\ 1Division of Neurophysiology, National Institute for Medical Research, London NW7 1AA, United Kingdom, and \\ 2Department of Sensorimotor Systems, Division of Neuroscience, Imperial College School of Medicine, London W6 8RF, \\ United Kingdom
}

Spatiotemporal correlations in the pattern of spontaneous and evoked retinal ganglion cell (RGC) activity are believed to influence the topographic organization of connections throughout the developing visual system. We have tested this hypothesis by examining the effects of interfering with these potential activity cues during development on the functional organization of binocular maps in the Xenopus frog optic tectum. Paired recordings combined with cross-correlation analyses demonstrated that exposing normal frogs to a continuous $1 \mathrm{~Hz}$ of stroboscopic illumination synchronized the firing of all three classes of RGC projecting to the tectum and induced similar patterns of temporally correlated activity across both lobes of the nucleus. Embryonic and eye-rotated larval animals were reared until early adulthood under equivalent stroboscopic conditions. The maps formed by each RGC class in the contralateral tectum showed normal topography and stratification after strobe rearing, but with consistently enlarged multiunit receptive fields. Maps of the ipsilateral eye, formed by crossed isthmotectal axons, showed significant disorder and misalignment with direct visual input from the retina, and in the eyerotated animals complete compensatory reorientation of these maps usually induced by this procedure failed to occur. These findings suggest that refinement of retinal arbors in the tectum and the ability of crossed isthmotectal arbors to establish binocular convergence with these retinal afferents are disrupted when they all fire together. Our data thus provide direct experimental evidence that spatiotemporal activity patterns within and between the two eyes regulate the precision of their developing connections.

Key words: retinal ganglion cell; nucleus isthmi; visual topography; stroboscopic illumination; correlated activity; synaptic plasticity; Xenopus laevis
Activity contributes importantly to the organization of synaptic connectivity at many levels of the developing visual system. For example, topographic projections from the retina and between different visual centers undergo activity-dependent refinement during development, in which connections most appropriate for visual information processing become stabilized and misplaced inputs are withdrawn (for review, see Udin and Fawcett, 1988; Constantine-Paton et al., 1990; Rauschecker, 1991; Goodman and Shatz, 1993). It is generally proposed that synchronous activity between convergent inputs reinforces developing connections, whereas asynchrony leads to their removal. Two distinct sources of afferent activity, with topographical origins needed to mediate these processes, now have been identified; correlated spontaneous firing of neighboring retinal ganglion cells (RGCs) may drive structural refinements of primary retinal maps, and correlated visually evoked activity in the two eyes appears to be necessary for organizing binocularly convergent projections.

Although these proposals enjoy considerable theoretical support, the experimental evidence remains indirect. Previous work on the formation of topographic projections from the contralateral and ipsilateral eyes onto the frog midbrain tectum typifies this problem. Activity clearly influences the organization of ret-

\footnotetext{
Received Sept. 16, 1997; revised Nov. 21, 1997; accepted Dec. 2, 1997.

This research was supported by the Medical Research Council.

Correspondence should be addressed to Dr. Simon Grant, Department of Sensorimotor Systems, Division of Neuroscience, Imperial College School of Medicine, Fulham Palace Road, London W6 8RF, UK.

Dr. Brickley's present address: Department of Pharmacology, University College London, Gower Street, London WC1E 6BT, UK.

Copyright (C) 1998 Society for Neuroscience $0270-6474 / 98 / 181491-14 \$ 05.00 / 0$
}

inal and crossed isthmotectal connections underlying these projections (see Fig. 1), because the refinement and proper alignment of the two maps are disrupted when afferent activity or synaptic activation of tectal NMDA receptors is reduced (Cline and Constantine-Paton, 1989, 1990; Grant and Keating, 1989b). These procedures also block more extreme forms of connectional plasticity in the two pathways under conditions in which between-eye activity correlations are assumed to be altered significantly, such as when two retinal projections form eye-specific stripes in one tectum (Reh and Constantine-Paton, 1985; Cline et al., 1987), and the ipsilateral map changes orientation after early eye rotation in Xenopus (Keating and Feldman, 1975; Scherer and Udin, 1989; Grant and Keating, 1992). However, the main treatment effects in these studies were on the overall level or balance of neural activity, rather than on its spatiotemporal pattern or degree of synchrony, so the connectional disruptions cannot be attributed specifically to interference with correlated activitybased mechanisms.

To test this possibility more directly, we generated abnormal spatiotemporal patterns of afferent activity in the developing Xenopus tectum by stimulating animals under constant stroboscopic light. Previous studies have reported connectional disorders after similar stimulation of developing (Berman and Payne, 1985; Grigonis and Murphy, 1991; Schmidt and Buzzard, 1993) and regenerating (Schmidt and Eisele, 1985; Cook, 1987) visual pathways, but the studies provided no evidence to support the assumption that activity was correlated in the species used. We demonstrate that during stroboscopic illumination RGC axons fire in synchronized bursts, which correlate spontaneous and 
A

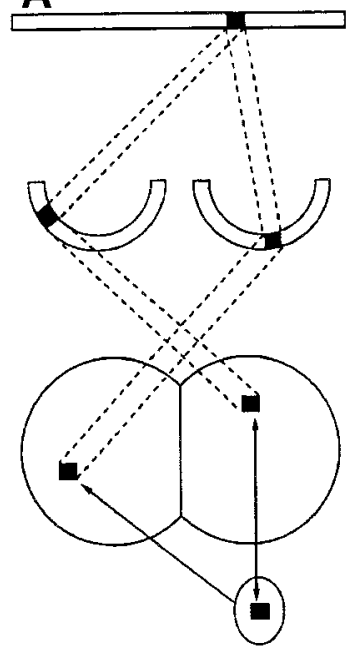

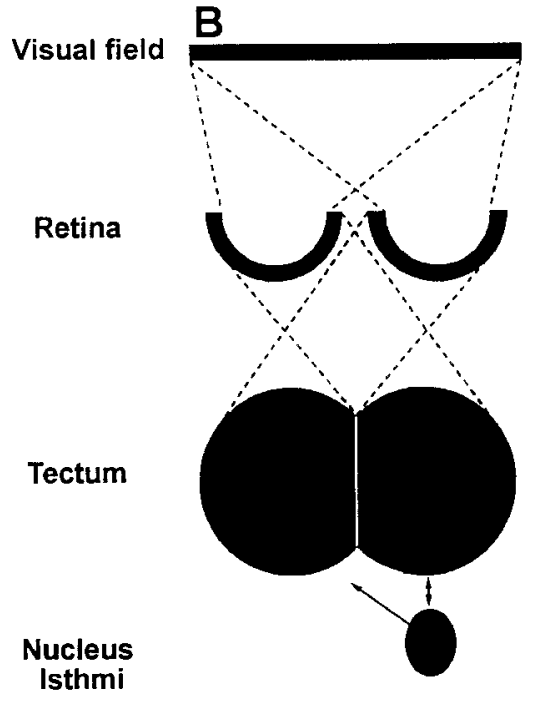

Figure 1. Schematic illustration of the topographic projections from the two eyes onto the frog tectum and predicted effects of stroboscopic stimulation on spatiotemporal firing patterns. $A$, In normal frogs the retina forms a point-to-point map across the opposite tectum, with the axons of neighboring RGCs terminating on adjoining tectal cells. Corresponding tectal positions are linked by an "intertectal" relay, involving uncrossed tecto-isthmic and crossed isthmotectal axons, which supply each lobe with a convergent point-to-point map of the ipsilateral eye. Consequently, a localized stimulus in the binocular field coactivates convergent retinal and crossed isthmotectal inputs. $B$, Stroboscopic illumination should synchronize activity in both eyes, subverting spontaneous and evoked activity correlations that may be involved in refining retinal and crossed isthmotectal connections. Note that, for clarity, the intertectal relay associated with the left nucleus isthmi has been omitted, as has the postoptic commissure in which crossed isthmotectal axons actually decussate.

evoked activity right across the tectum, rather than just locally as under more natural stimulus conditions. Electrophysiological mapping assays demonstrated that the precision and plasticity of retinotectal and crossed isthmotectal connections were disrupted significantly in normal and early eye-rotated frogs reared under our experimental conditions. The disruptions, although generally less severe, are similar in nature to those observed when activity in these developing pathways is reduced.

\section{MATERIALS AND METHODS}

Rearing and recording procedures. Xenopus embryos were obtained after injection of human chorionic gonadotrophin into the dorsal lymph sac of adult breeding pairs. Embryos derived from each mating were divided at hatching (stage 35/36; Nieuwkoop and Faber, 1967) into two groups: one group was reared normally under natural diurnal lighting conditions, and the other was raised in an environment consisting of continuous stroboscopic illumination (strobe-reared). Postembryonic animals of each group were maintained initially in opaque, open-top tanks containing oxygenated Stearns solution and fed with strained baby food. On reaching larval stages 56-58, individual animals were transferred into separate black perspex containers fitted with transparent perforated lids so that incident light could enter the box only from above. They were fed tubifex worms twice weekly, when their water was replaced, and remained on this regime until late juvenile-young adult life, at $1-1 \frac{1}{2}$ years postmetamorphosis (PM).

Strobe-reared animals were placed inside a light-tight cabinet with featureless walls housing the xenon strobe unit suspended from its roof. Strobe flashes were maintained at a constant frequency of $1 \mathrm{~Hz}$ and 10 $\mu$ sec duration (at $1 / 2 V_{\max }$ ) throughout the rearing period. The intensity of illumination varied from $\sim 0.5 \mathrm{~kW} / \mathrm{m}^{2}$ at the edge of the cabinet to $\sim 10$ $\mathrm{kW} / \mathrm{m}^{2}$ directly below the unit ("average" daylight ranges from $\sim 1-3$ $\mathrm{kW} / \mathrm{m}^{2}$ ). For this reason, animals were switched at feeding times to different positions in the cabinet. To minimize further the availability of visual contrast information during this regime, we conducted animal maintenance away from the cabinet under conditions of dim red illumination (compare Keating et al., 1986).

Uniocular eye rotations of $90-180^{\circ}$ were performed on normally reared stages 56-58 larval animals, anesthetized by immersion in MS222 (tricaine-methanesulphate; 1:1500 in aqueous solution), as previously described (Grant and Keating, 1992). Once the operated eye was repositioned successfully, the animals were allowed to recover fully and then either were returned to their original environment or were strobe-reared, as above, until the recording experiment.

Electrophysiological recordings, undertaken to assess both the acute and long-term effects of exposure to stroboscopic illumination, followed several standardized procedures. Young adult frogs were anesthetized by injection of MS222 (2-5 mg, i.p). The optic tectum was exposed by a partial craniotomy and photographed at $50 \times$ magnification onto Polaroid film. Animals were placed at the center of an Aimark projection perimeter (Bausch and Lomb, London, UK), with the optic axis of one eye centered on the origin of the perimeter arc. Their bodies were covered with tissue paper that was saturated with oxygenated MS222 solution to ensure that adequate anesthesia was maintained throughout the recording session. Responses to various visual stimuli were recorded with tungsten-in-glass microelectrodes of tip diameter $2-5 \mu \mathrm{m}$ and impedance $0.5-2 \mathrm{M} \Omega$ inserted into the superficial tectal neuropil, guided by reference to a grid drawn on the photographic enlargement of its surface. The responses were amplified conventionally and monitored on an oscilloscope and through an audio amplifier. Window discriminators were used to time the arrival of action potentials at recording sites and to eliminate background noise levels, as required.

Effects of stroboscopic illumination on temporal firing patterns in the tectum. These recording techniques selectively sample from the active zones of axonal arbors: that is, RGC arbors from the contralateral eye (George and Marks, 1974) and crossed isthmotectal arbors via the ipsilateral eye (Udin and Keating, 1981). Consequently, we were able to evaluate the responses of normal RGCs to stroboscopic illumination by recording from their arbors in the optic tectum. The Xenopus tectum receives projections from three classes of RGC, from which the axons terminate in separate strata of the superficial layers $(9-8)$ and from which the responses to conventional visual stimuli differ markedly (Maturana et al., 1960; Chung et al., 1975; Keating et al., 1986). Class I or "sustained" units are located just below the pial surface and fire in prolonged bursts when a small $\left(\sim 5^{\circ}\right)$ visual stimulus is moved into their excitatory receptive field (RF) and held stationary there, but they are relatively insensitive to light onset or offset. Class III or "event" units occupy the next level. They respond optimally to the movement of small $\left(5-10^{\circ}\right)$ visual stimuli within their RF and also give strong transient "ON" and "OFF" responses to changes in luminance. Class IV or "dimmer" units are found deepest down and are responsive to large $\left(\sim 20^{\circ}\right)$ moving stimuli, but their cardinal response involves sustained bursts of activity to stepwise decrements in RF illumination.

A requirement for initiating the strobe-rearing experiments was that each of these RGC classes should respond consistently to the chosen temporal frequency of stroboscopic illumination and that it should alter the spontaneous discharges of each. In preliminary experiments (data not shown) we monitored the single-unit responses of each RGC class to brief (5-10 $\mathrm{min}$ ) presentations of a range of strobe frequencies (between 0.1 and $10 \mathrm{~Hz}$ ). These recordings indicated that frequencies of $\leq 0.5$ and of $\geq 2.5 \mathrm{~Hz}$ were unsuitable for rearing purposes; all unit classes responded to low-frequency strobe flashes, but the interstimulus intervals were too long to prevent the return of spontaneous activity; at the higher frequencies, only event units were capable of consistent responses. Another requirement was that the strobe-induced RGC firing should activate postsynaptic tectal cells. Because we are unable to record from these with our techniques, this was assessed indirectly by examining the selective outflow of their activity via the tecto-isthmic and crossed isthmotectal pathways (Fig. 1A). In these experiments frogs were enucleated monocularly and multiunit recordings made from just below the pial surface in the tectum ipsilateral to the remaining eye, where the arbors of fine-caliber crossed isthmotectal axons terminate (Udin, 1989). Ipsilateral units are known to habituate during repetitive stimulation in anesthetized frogs, but successive responses to low-frequency $(\leq 1 \mathrm{~Hz})$ strobe flashes were obtained, indicating that these arbors were firing because of activation of cells in the opposite tectum.

Because these observations suggested that a $1 \mathrm{~Hz}$ frequency might confer optimal conditions for strobe rearing, a more detailed series of 
control experiments was undertaken to determine whether this strobe frequency could synchronize and correlate RGC firing during much longer exposures. In these experiments two microelectrodes were used for simultaneous paired recordings in the same or opposite tectal lobes, with their depths and positions carefully adjusted to record multiunit activity from the same class of RGC having response fields that were either partially overlapping or completely nonoverlapping in visual space. Then the strobe unit was moved into position $\sim 33 \mathrm{~cm}$ from the animal, either within the region of RF overlap or at a strategic distance between the two nonoverlapping fields that optimized their firing to test flashes. Spontaneous discharges (in the dark) were monitored at the two recordings sites for 5-15 min before the strobe was activated, and responses to constant stroboscopic illumination $(10 \mu \mathrm{sec}$ duration at 1 $\mathrm{Hz}$ ) were recorded for a further period of 2-6 hr. Toward the end of the session the response or responses of one or both multiunits to a 5,10 , or $20^{\circ}$ black disk introduced into their RF or RFs also were recorded to evaluate any modulatory effects of visual contrasts on the strobe-induced firing pattern.

Signals from the two recording sites were processed through separate channels and logged for the entire course of the experiment with a CED 1401 (Cambridge Electronic Design, Cambridge, UK) laboratory interface on which on-line and subsequent analyses could be performed via an IBM computer. Strobe-induced changes in the temporal pattern of RGC firing were examined by depicting the data from each channel as raster plots showing the time of occurrence of individual spikes in relation to the strobe flash for every $1 \mathrm{sec}$ epoch of the experiment. Changes in firing rates were calculated from the number of spikes per second after each strobe flash. Cross-correlation (CC) analyses were performed on the simultaneously recorded responses. For this purpose one channel was treated as a "reference," and for each spike in this channel the times at which any spikes occurred in the other channel during the interval $0 \pm$ $500 \mathrm{msec}$ were computed, after dividing this channel into $2 \mathrm{msec}$ bins. The time-averaged CCs determined in this way from selected periods in each recording session were plotted as histograms showing the temporal phase and relative strengths of the correlations that were present.

To provide a quantitative indication of the degree of coincident firing occurring under the different conditions of these recordings, which subsumed differences in firing rates associated with them, we divided the average number of events occurring in the CC histograms at time $=0 \pm$ $10 \mathrm{msec}$ by the average number of noncoincident events (i.e., in the remaining bins at $t= \pm 10-500 \mathrm{msec}$ ) over the same sampling period. This measure was termed the "coincidence index" $\left(C I_{10}\right)$; increasing values $>1.0$ on this index indicate increasing degrees of in-phase, synchronous activity at the two recording sites (while disregarding any anti-phase or asynchronous relationships). As an indication of any broader temporal correlations that were present, a "correlation index" $\left(C I_{50}\right)$ also was calculated from the data by similarly comparing the events occurring at $t=0 \pm 50 \mathrm{msec}$ with those in the remaining bins. Our reason for selecting these particular intervals is that 10 and $50 \mathrm{msec}$ correspond, respectively, to the average initial delay and subsequent overlap in the activity evoked in the normal Xenopus tectum by ON/OFF stimuli at corresponding positions in the contralateral and ipsilateral eyes (Scherer and Udin, 1991). Either or both intervals thus may have physiological relevance for stabilizing the developing visual connections under investigation, as well as falling within known integration times for inducing long-term potentiation of synaptic strength after stimulating paired inputs (i.e., associative LTP) in the adult hippocampus (Levy and Steward, 1983; Gustafsson and Wigstrom, 1986). In these analyses we made no attempt to separate direct stimulus-induced correlations in firing from those arising via "effective connectivity" (Aertson et al., 1989 ) between the paired recording sites. The reason for this is that effective connectivity attributable to common input (e.g., onto neighboring class-specific RGCs) or to direct (e.g., intertectal) connections is more likely to exist at corresponding than at noncorresponding sites, and so the analysis should properly reflect this difference by including all possible sources of coincident or correlated activity. In fact, the completed analyses revealed no meaningful differences between the two indices used, so only the data relating to $C I_{10}$ are shown.

Effects of stroboscopic illumination on binocular map development. Visual inputs to the tectum were mapped at multiple recording sites in normal and strobe-reared frogs by using conventional visual stimuli presented against the uniform background of the perimeter arc and RFs plotted onto polar coordinate charts for future analyses. Initial efforts focused on the direct retinotectal projection from the contralateral eye. To assess its topographic order, we made stepwise electrode penetrations into the tectum, separated by $100-200 \mu \mathrm{m}$ across its surface dimensions and by $25-50 \mu \mathrm{m}$ in depth while plotting minimum response fields and classifying the sequence of units that were encountered. In some of these experiments and in later ones dedicated to the purpose, the RF sizes of single- and multiunits recorded at different depths were evaluated quantitatively, using computer-controlled methods of visual stimulation and data capture (Keating et al., 1986). These measures can provide an index of the detailed precision of the retinotectal map; enlarged multiunit RFs (MURFs), in the absence of changes in single-unit RF size, indicate that the RGCs projecting to a given tectal site arise from a wider territory than normal and/or that their arbors are more diffuse. To minimize other variables that can affect these measures, we used the same set of lowimpedance electrodes for all of the recordings in both groups of frog, and window discrimination of the amplified signals was always set at $100 \%$ above the noise level. RFs were plotted on a large television screen, positioned $38 \mathrm{~cm}$ from the stimulated eye, and covered an effective stimulus area of $64.5^{\circ}$ in the nasotemporal axis and $34.5^{\circ}$ in the superoinferior axis of its visual field. The visual stimulus (a $6^{\circ}$ black square) was moved either horizontally or vertically in $1.5^{\circ}$ steps across the screen at a constant speed of $35^{\circ} \mathrm{sec}$. Spikes occurring during each traverse were timed and stored on computer. The direction of stimulus traverse was interleaved randomly between runs, with a least three sets of traverses completed for each possible direction. For each MURF plotted, electrode depth was set to ensure that only one RGC class was being sampled and that the response contained at least three separate units, as revealed by differences in their spike height and width. To analyze the data, we produced two-dimensional matrix representations of the screen, in which the effective stimulus area was divided into $1.5^{\circ} \times 1.5^{\circ}$ pixels and the number of spikes per pixel was presented as an element of the matrix. The RF size was measured by pooling matrices: the horizontal diameter by combining matrices from the two vertical directions of stimulus movement, the vertical diameter from its two horizontal directions of movement, and its area from the outline of the combined matrices. To avoid inclusion of elements arising from occasional spontaneous or artifactual bursts of spikes, we considered only pixels containing $\geq 10 \%$ of the maximum number of spikes per pixel to be genuine components of the RF.

In other animals of both groups, including those with early eye rotations, the visual projections from both eyes to one tectum were mapped to examine the topographic order of the crossed isthmotectal map from the ipsilateral eye and to assess its spatial alignment with the direct retinal map. In these experiments we plotted minimum response fields in the contralateral and ipsilateral eyes independently on the polar coordinate system while alternately covering the nontested eye with an opaque shield. The center of each RF was defined as the geometric center of the response field, a position that typically approximated the point of maximal activation. Spatial alignment between the two maps was quantified by calculating the disparity (in degrees) between the binocular RF centers at each tectal site receiving input from the two eyes. Disparity was expressed both by its absolute value and by its horizontal (nasotemporal) component. Data derived from the strobe-reared frogs were compared with the controls from the present investigation and also with those previously obtained from age-matched dark-reared frogs in which these features were found to be disrupted systematically (Grant and Keating, 1989 b). These and other statistical comparisons were conducted with the software package SIGMA STAT.

\section{RESULTS}

The results are presented in two sections. First, we provide evidence that exposure to $1 \mathrm{~Hz}$ of stroboscopic illumination interferes with the temporal pattern of RGC firing, in support of the rationale for the rearing experiments (Fig. $1 B$ ). Second, we examine the consequences of development under these conditions for the organization and plasticity of binocular maps in the optic tectum.

\section{Control experiments: correlated firing in the tectum}

Simultaneous recordings were undertaken in 12 normal frogs to monitor the effects of prolonged $1 \mathrm{~Hz}$ of stroboscopic illumination on RGC firing patterns. The recordings were obtained from pairs of sustained $(n=4)$, event $(n=6)$, or dimmer $(n=2)$ RGC classes, comprising six pairs from corresponding sites with spa- 


\begin{tabular}{|c|c|c|c|c|c|c|c|c|c|c|}
\hline \multicolumn{2}{|c|}{$\begin{array}{l}\text { Corresponding sites } \\
\text { Paired units recorded }\end{array}$} & \multirow[b]{2}{*}{ Location } & \multicolumn{3}{|c|}{ Firing rate (spikes/sec) mean \pm SD } & \multirow[b]{2}{*}{$\begin{array}{l}\text { Visual } \\
\text { slim. }\end{array}$} & \multicolumn{2}{|c|}{ Coincidence index } & \multirow[b]{2}{*}{$\begin{array}{l}\text { Entrained } \\
(2 \mathrm{hr})\end{array}$} & \multirow[b]{2}{*}{$\begin{array}{l}\text { Visual } \\
\text { stim. }\end{array}$} \\
\hline I.D. & Type & & Spont. & Strobe onset & $\begin{array}{l}\text { Entrained } \\
(2 \mathrm{hr})\end{array}$ & & Spont. & $\begin{array}{l}\text { Strobe } \\
\text { onset }\end{array}$ & & \\
\hline \multirow[t]{2}{*}{ str-08 } & Sustained & $\mathrm{R}, \mathrm{R}$ & $4 \pm 1$ & $43 \pm 28$ & $56 \pm 5$ & $87 \pm 30$ & 2.7 & 2.7 & 2.6 & 2.6 \\
\hline & & & $5 \pm 1$ & $67 \pm 31$ & $39 \pm 2$ & $55 \pm 18$ & & & & \\
\hline \multirow[t]{2}{*}{ str-06 } & Event & $\mathrm{R}, \mathrm{R}$ & $12 \pm 2$ & $58 \pm 36$ & $23 \pm 2$ & $47 \pm 8$ & 1.4 & 1.9 & 2.4 & 1.9 \\
\hline & & & $15 \pm 2$ & $119 \pm 36$ & $44 \pm 5$ & $73 \pm 13$ & & & & \\
\hline \multirow[t]{2}{*}{ str-10 } & Event & $\mathrm{R}, \mathrm{R}$ & $4 \pm 1$ & $65 \pm 15$ & $81 \pm 5$ & $150 \pm 30$ & 1.2 & 1.9 & 2.2 & 1.7 \\
\hline & & & $5 \pm 2$ & $89 \pm 24$ & $82 \pm 9$ & $192 \pm 38$ & & & & \\
\hline \multirow[t]{2}{*}{ str-04 } & Dimmer & $\mathrm{R}, \mathrm{R}$ & $15 \pm 1$ & $89 \pm 19$ & $86 \pm 3$ & n.r. & 1.5 & 2.8 & 2.8 & $\mathrm{x}$ \\
\hline & & & $16 \pm 2$ & $82 \pm 9$ & $70 \pm 6$ & n.r. & & & & \\
\hline \multirow[t]{2}{*}{ str-05 } & Sustained & $\mathrm{L}, \mathrm{R}$ & $11 \pm 4$ & $77 \pm 43$ & $73 \pm 3$ & $143 \pm 23$ & 1 & 2.6 & 2.9 & 1.5 \\
\hline & & & $5 \pm 1$ & $30 \pm 17$ & $35 \pm 2$ & $53 \pm 14$ & & & & \\
\hline \multirow[t]{4}{*}{ str-12 } & Event & $\mathrm{L}, \mathrm{R}$ & $10 \pm 2$ & $31 \pm 8$ & $41 \pm 4$ & $63 \pm 10$ & 1.1 & 2.8 & 3.1 & 2.4 \\
\hline & & & $19 \pm 3$ & $54 \pm 15$ & $47 \pm 4$ & $116 \pm 23$ & & & & \\
\hline & & & & & & Mean & 1.5 & 2.5 & 2.7 & 2.0 \\
\hline & & & & & & SD & 0.6 & 0.4 & 0.3 & 0.5 \\
\hline \multicolumn{11}{|c|}{ Noncorresponding sites } \\
\hline \multirow[t]{2}{*}{ str- 03} & Sustained & $\mathrm{R}, \mathrm{R}$ & $8 \pm 1$ & $66 \pm 10$ & $57 \pm 2$ & $96 \pm 13$ & 0.9 & 1.2 & 1.8 & 1.3 \\
\hline & & & $5 \pm 2$ & $70 \pm 24$ & $51 \pm 3$ & $\mathrm{x}$ & & & & \\
\hline \multirow[t]{2}{*}{ str-02 } & Event & $\mathrm{R}, \mathrm{R}$ & $11 \pm 3$ & $59 \pm 16$ & $35 \pm 3$ & $56 \pm 6$ & 1 & 1.6 & 2.9 & 2.8 \\
\hline & & & $16 \pm 7$ & $70 \pm 23$ & $57 \pm 3$ & $\mathrm{x}$ & & & & \\
\hline \multirow[t]{2}{*}{ str-07 } & Dimmer & $\mathrm{R}, \mathrm{R}$ & $13 \pm 3$ & $102 \pm 25$ & $91 \pm 5$ & $140 \pm 17$ & 0.9 & 2.8 & 3 & 2.6 \\
\hline & & & $21 \pm 6$ & $181 \pm 36$ & $160 \pm 11$ & $\mathrm{x}$ & & & & \\
\hline \multirow[t]{2}{*}{ str- 01} & Sustained & $\mathrm{L}, \mathrm{R}$ & $7 \pm 1$ & $69 \pm 12$ & $34 \pm 2$ & $66 \pm 12$ & 1.7 & 2.3 & 3.5 & 2.3 \\
\hline & & & $6 \pm 1$ & $33 \pm 6$ & $21 \pm 3$ & $\mathrm{x}$ & & & & \\
\hline \multirow[t]{2}{*}{ str-09 } & Event & $\mathrm{L}, \mathrm{R}$ & $6 \pm 2$ & $79 \pm 13$ & $51 \pm 7$ & $92 \pm 17$ & 1.1 & 1.8 & 3.1 & 2.8 \\
\hline & & & $6 \pm 3$ & $45 \pm 8$ & $29 \pm 3$ & $\mathrm{x}$ & & & & \\
\hline \multirow[t]{4}{*}{ str-11 } & Event & $\mathrm{L}, \mathrm{R}$ & $3 \pm 1$ & $81 \pm 65$ & $33 \pm 5$ & $55 \pm 10$ & 1 & 1.1 & 2.1 & 1.6 \\
\hline & & & $4 \pm 1$ & $66 \pm 41$ & $59 \pm 2$ & $\mathrm{x}$ & & & & \\
\hline & & & & & & Mean & 1.1 & 1.8 & 2.7 & 2.2 \\
\hline & & & & & & $\mathrm{SD}$ & 0.3 & 0.7 & 0.6 & 0.6 \\
\hline
\end{tabular}

R, L, Right, left tectum; n.r., no response to visual stimulation; $x$, unit not stimulated.

tially overlapping RFs and six from noncorresponding ones with disparate, completely nonoverlapping RFs. These and other details are summarized in Table 1.

To establish a baseline against which any strobe-induced effects could be compared, we conducted CC analyses of visually evoked and spontaneous activity for each RF pair before activating the strobe. Figure $2 A$ shows typical responses obtained from corresponding recording sites when a visual stimulus was introduced into the region of RF overlap. The CC histograms derived from such data always revealed a broad (100-200 msec) peak of correlated activity centered at $t=0$, with a $C I_{10}$ between 2.1 and 3.5, indicating synchronous firing at the two tectal sites. This pattern of correlated activity could be replicated at noncorresponding tectal sites by perfect in-phase stimulation of the two disparate RFs, but with more natural out-of-phase stimulation their activity was anticorrelated with a similarly broad, but asymmetric, peak in the $\mathrm{CC}$ histogram and sometimes with a depression at $t=0$, indicative of noncoincident firing $\left(C_{10} \leq 0.8\right)$. By contrast, $\mathrm{CCs}$ derived from visual stimulation of only one RF of the nonoverlapping pair were always flat (Fig. 2B), indicating that correlations between evoked activity at stimulated tectal sites and spontaneous firing at other sites were random $\left(C I_{10}=1 \pm 0.1\right)$.
Spontaneous activity generally was maintained at low levels regardless of RGC class, both in the light (Fig. 2) and in the dark (Fig. 3), with just occasional bursts of spikes detected. Nonetheless, the spontaneous discharges occurring at neighboring locations in the same tectum consistently exhibited a degree of synchrony $\left(C I_{10}>1.0\right.$; Table 1$)$ presumably arising via effective connectivity, whereas random activity correlations were present among most of the other paired sites (compare Fig. $2 B$ ).

\section{Stroboscopic illumination entrains the firing of all three RGC classes}

All 24 sustained, event, or dimmer unit types that were examined acquired and maintained similar patterns of entrained firing during prolonged exposure to $1 \mathrm{~Hz}$ of stroboscopic illumination. The raster plots in Figure 3 illustrate the time course of this entrainment effect for representatives of each RGC class. Initial responses to the strobe usually were vigorous but variable in rate (Table 1) and temporal pattern. With continued exposure the firing rate became more stable, and a distinctly triphasic response pattern emerged, comprising short, middle, and long latency bursts of periodic activity with silent or near-silent periods in between, each element of which was reproduced after successive 
A

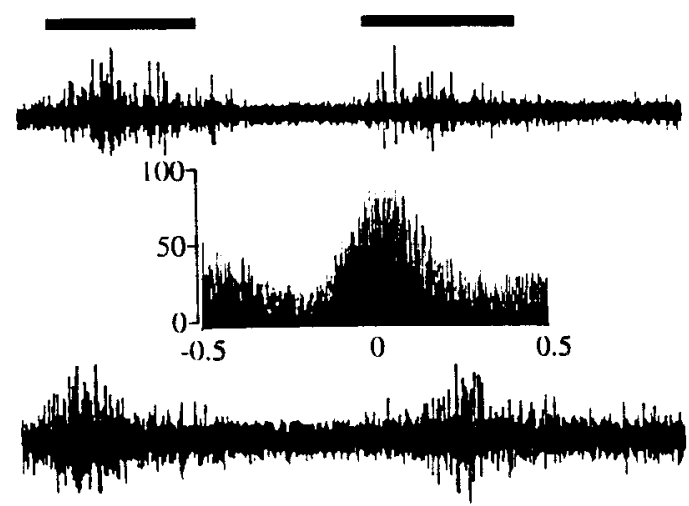

B

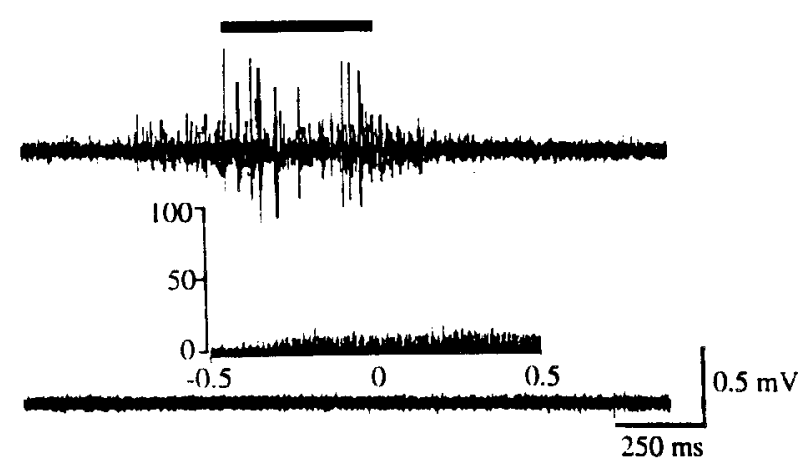

Figure 2. Correlations in firing at corresponding and noncorresponding tectal sites evoked by localized binocular visual stimulation. $A$, The top and bottom traces show responses recorded simultaneously from paired sites in opposite tectal lobes receiving corresponding retinal input during stimulation of their overlapping RFs (with a $10^{\circ}$ black disk moved against the background of the illuminated perimeter arc). The top bars indicate stimulation periods and refer to both traces. The middle panel inset shows the time-averaged $\mathrm{CC}$ histogram computed from these recording data: the abscissa (in seconds) is divided into 2 msec bins, and the ordinate indicates the number of events per bin. A broad peak of correlated activity is centered at $t=0( \pm 100 \mathrm{msec}): C I_{10}=2.2 . \mathrm{B}$, Simultaneous recording from sites in opposite tectal lobes receiving noncorresponding retinal input during visual stimulation of one RF (top trace) of the nonoverlapping pair. The CC histogram (middle panel inset) derived from this recording indicates that the correlation between the evoked and spontaneous activity is random: $C I_{10}=1.0$. Other conventions are as in $A$. Calibration refers to all traces.

strobe flashes. The triphasic latency profile was remarkably similar across RGC classes (see also Fig. 5). The early and middle components of the response were most prominent at 100-150 msec and at 300-500 msec poststimulus, respectively, and the late component began at $\sim 700 \mathrm{msec}$, usually to be curtailed only by the next strobe flash in the sequence. Moreover, the entrained firing patterns remained essentially invariant and without obvious contamination by spontaneous discharges until the recording was interrupted. These results thus imply that stroboscopic illumination causes RGC axons in all regions and depths of the Xenopus tectum to fire in synchrony.

The response of normal RGCs to $1 \mathrm{~Hz}$ of stroboscopic illumination has been examined previously during several minutes of continuous recording from the goldfish tectum and consisted of just a single short latency burst, $\sim 50-200 \mathrm{msec}$ in duration, followed by quiescence (Schmidt and Eisele, 1985). The more intermittent bursting activity in Xenopus almost certainly results
A

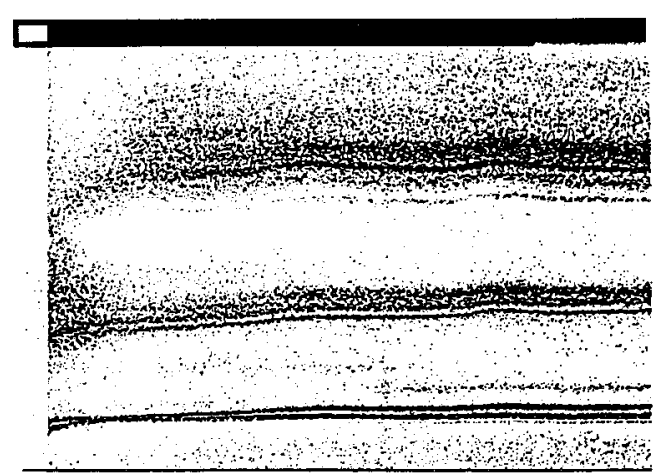

B

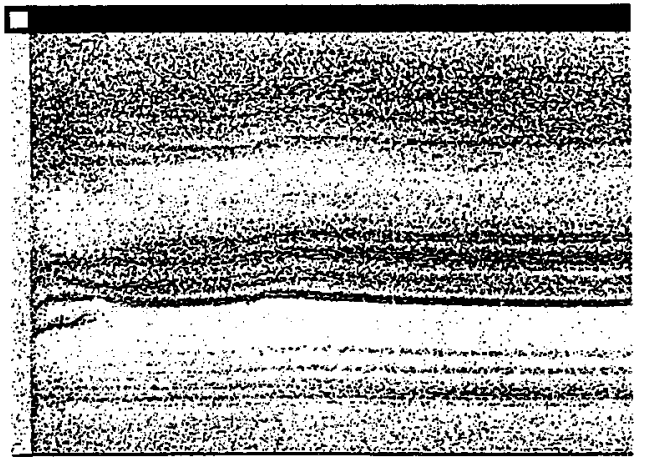

$\mathrm{C}$

$0.2 \mathrm{~s}$

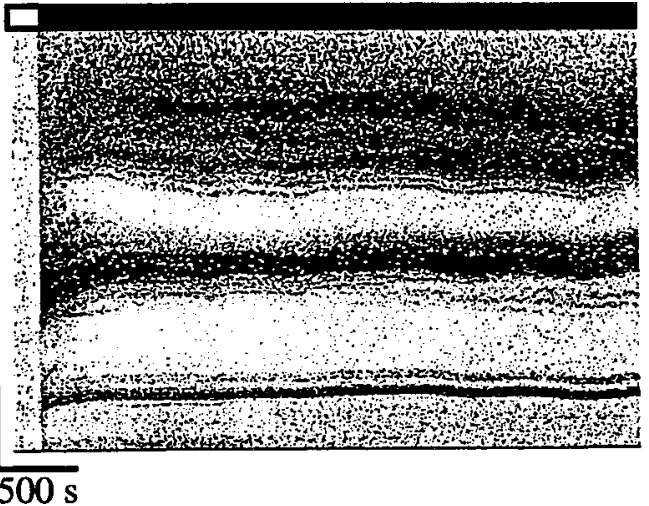

Figure 3. Entrained patterns of RGC firing induced by exposure to a continuous $1 \mathrm{~Hz}$ of stroboscopic illumination in $(A)$ sustained, $(B)$ event, and $(C)$ dimmer unit classes. In these raster plots each dot represents an action potential recorded during the first $3 \mathrm{hr}$ of an uninterrupted recording session in three different experiments $(\mathrm{A}, \mathrm{B}$, and $\mathrm{C}$; one of the unit pairs str-03, str-02, and str-07). The $x$-axes represent the time (in seconds) for this part of each recording session, and the $y$-axes correspond to the 1 sec interval between strobe flashes (occurring at the abscissa in each plot). For the period indicated by the short open bar at the top of each panel, the frog was maintained in darkness while spontaneous discharges were monitored; the long black bar indicates the period of exposure to stroboscopic illumination. Within a few minutes of strobe onset, an entrained triphasic response pattern emerges and is maintained throughout the recording period. Calibration (bottom left) refers to all panels.

from differences in intraretinal processing between frogs and fish, a difference that begins in the photoreceptor layer, which is known to be rod- and cone-dominated, respectively, in these species. Indeed, intermittent periodic bursts of activity, lasting for as long as $1 \mathrm{sec}$ poststimulus, also appear to characterize the firing patterns of frog RGCs responding to the onset and offset of bright 
light flashes (25-1000 msec duration), which are confined to their excitatory RF [Rana, Stiles et al. (1985); Xenopus, S. Brickley and S. Grant, unpublished data]. The main difference between these responses and those elicited by (more transient and diffuse) strobe flashes is that the earliest component (up to $250 \mathrm{msec}$ poststimulus) is more periodic and begins at a shorter (50-75 msec) latency. The strobe-entrained firing pattern of Xenopus RGCs thus appears to be a variant on their normal temporal response to abrupt changes in illumination.

\section{Stroboscopic illumination induces temporal correlations in firing at all tectal locations}

Representative data showing the effects of stroboscopic entrainment on correlations in firing at corresponding and at noncorresponding tectal locations are presented in Figure 4. CC histograms computed from all of the paired recording sites in positions of tectal correspondence (Fig. 4A), whether in the same or opposite sides of the brain, exhibited a sharp (20-50 msec) peak of coincident activity centered at $t=0$ as soon as the strobe flashes began within their region of RF overlap (Table 1). With more prolonged exposure and consequent entrainment of firing at the two recording sites, this correlated firing usually improved but was accompanied by the emergence of secondary peaks of anticorrelated activity (at $> \pm 50 \mathrm{msec}$ ), the number and distribution of which depended on subtle phase differences in the periodic activity of the two strobe-entrained responses. At paired noncorresponding tectal locations, correlations in firing were closer to random at strobe onset, but a similar pattern of correlated and anticorrelated firing emerged during strobe entrainment (Fig. $4 B$ ). Most strikingly, a sharp peak of coincident activity, at $t=$ $0 \pm 10 \mathrm{msec}$, appeared in all of the CC histograms computed from these paired recordings once entrainment was well established (Table 1). These results indicate, therefore, that stroboscopic synchronization of RGC firing induces similar temporal patterns of correlated and anticorrelated activity at all tectal locations.

\section{Effects of visual contrasts on the rate and temporal pattern of stroboscopically entrained firing}

Although we took steps to limit visual contrast information in the strobe-rearing environment, some potential sources of this (e.g., the air holes in the animal container lids and food supplied) could not be excluded. To evaluate their possible effects on strobeinduced firing patterns, we introduced visual stimuli (black disks) into the RF or RFs of each unit pair once stable strobe entrainment and activity correlations had become established. Figure 5, $A$ and $C$, shows segments of the raster plots for unit pairs of each RF condition for the period immediately before, during, and after visual stimulation of both (overlapping) or one of their (nonoverlapping) RFs. The visual contrast significantly increased the rate of firing of the stimulated units (by 50-100\%; Table 1), most prominently in the interval between 200 and $700 \mathrm{msec}$ after each strobe flash. As indicated in the raster plots of Figure 5 and confirmed by analyses of cumulative poststimulus time histograms compiled from these recording periods (data not shown), this contrast-evoked activity was superimposed on the middle component of the strobe-entrained firing and on the silent periods on either side of it, with little effect on the early or late components of the entrained response.

This increased firing would be expected to impact on the pattern of activity correlations, because the added activity presents more opportunities for temporal coincidences and noncoincidences to be established. However, $\mathrm{CC}$ histograms computed
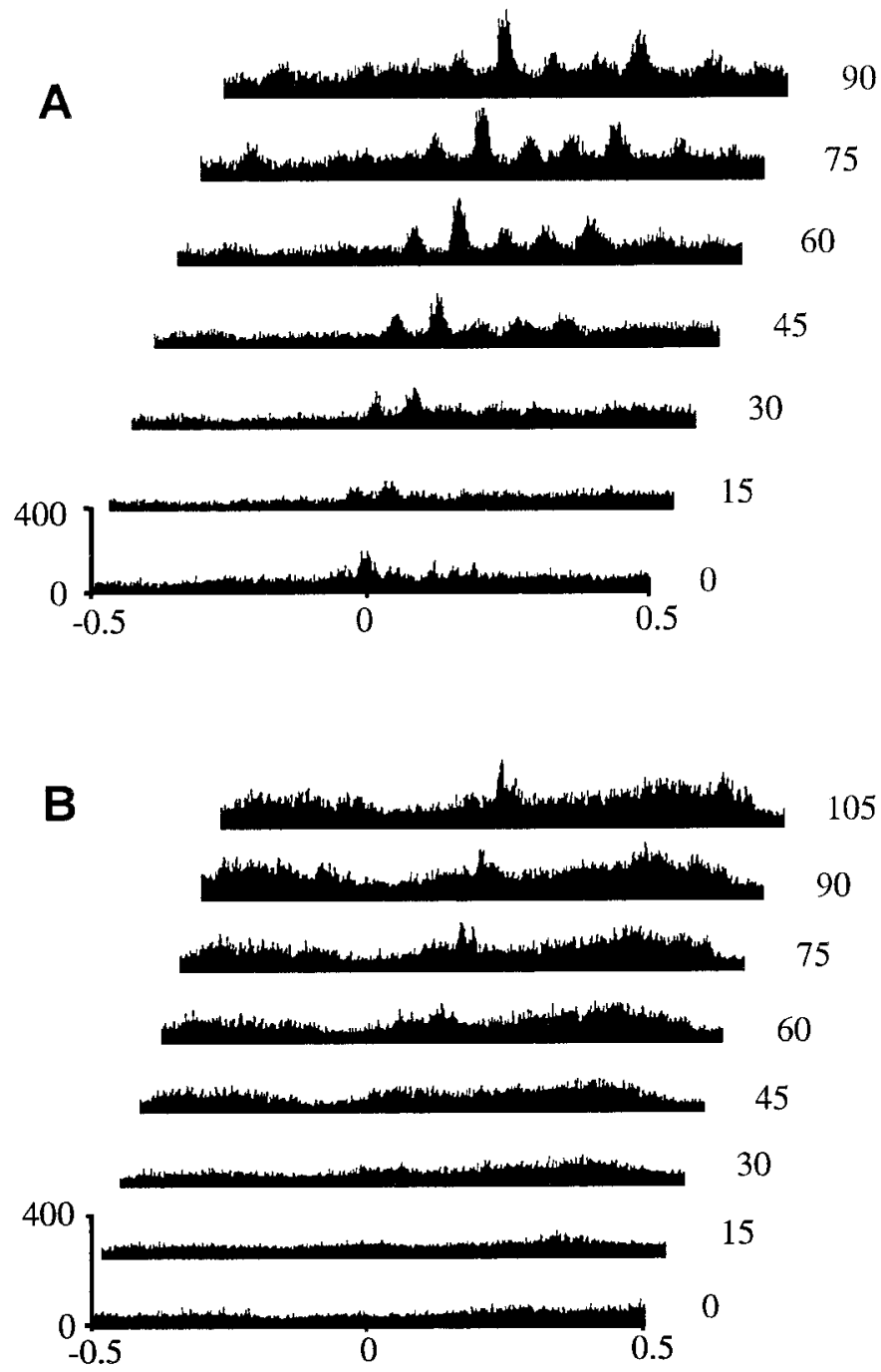

Figure 4. Stroboscopic entrainment leads to similar temporal correlations in firing at $(A)$ corresponding and $(B)$ noncorresponding tectal sites. Each histogram shows time-averaged CCs computed from $60 \mathrm{sec}$ episodes of simultaneous recording from the onset of stroboscopic illumination (at time 0 , as indicated, right) and at subsequent 15 min intervals during the entrainment of the responses. In $A$, a sharp peak of coincident activity was present throughout the recording, which increased slightly during strobe entrainment (unit pair, str-05); in $B$, activity was correlated randomly at strobe onset, but a peak of coincident activity emerged as a result of strobe entrainment (unit pair, str-11). Calibration conventions, as in Figure 2 insets, refer to each histogram in the landscaped presentations.

for the period of visual contrast stimulation, although differing markedly from those obtained for comparable stimulation under normal viewing conditions (see Fig. $2 A$ ), showed remarkably similar patterns of correlated and anti-correlated activity to those derived from the strobe-entrained periods immediately before and afterward. Indeed, the main difference appeared to be in the height of the peaks, all of which were elevated in the CCs computed from the responses during contrast stimulation, suggesting that absolute levels of both coincident and noncoincident activity were increased. This was confirmed by subtracting one $\mathrm{CC}$ from another (e.g., during contrast stimulation minus before). As typified in Figure 5, $B$ and $D$, the residual histograms were flat for both overlapping and nonoverlapping RF conditions, indicating that contrast-evoked correlations in firing were essentially random (compare Fig. 2B) during stroboscopic entrainment. 
A
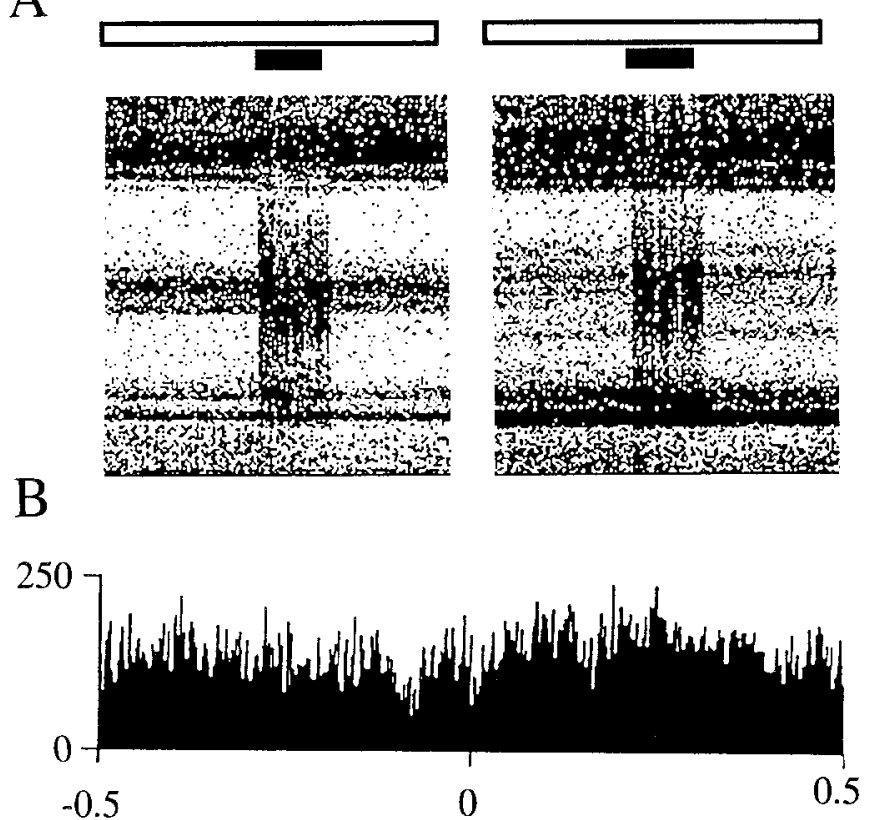

C

$\mathrm{D}$
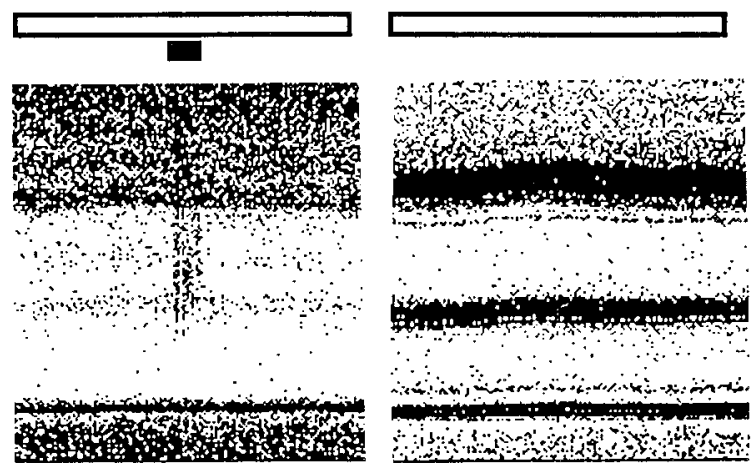

250

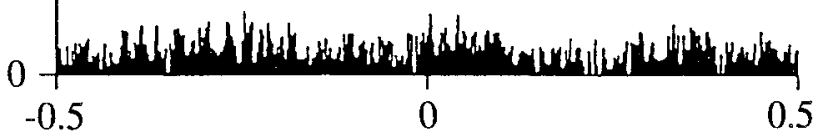

Figure 5. Effects of localized binocular visual stimulation on stroboscopic entrainment and correlated firing at $(A, B)$ corresponding and $(C, D)$ noncorresponding tectal sites. The raster plots in each top panel $(A, C)$ show 10 min segments (open bar above) of strobe-entrained responses recorded toward the end of a $4 \mathrm{hr}$ exposure to a continuous $1 \mathrm{~Hz}$ of stroboscopic illumination. During the middle of the period shown (solid black bar above), a visual stimulus ( $10^{\circ}$ diameter black disk) was moved against the background of the perimeter arc through the region of RF overlap (in $A$; str-10) or through one RF of the nonoverlapping pair (left, in $C$; str-11) while the strobe continued to flash. Additional activity evoked by this contrast stimulation is evident in the raster plots and is associated with an increase in the firing rate of the stimulated units (see Table 1 ). $B$ and $D$ show residual time-averaged CC histograms, produced by subtracting the cross-correlations in firing for the $60 \mathrm{sec}$ periods immediately before and during contrast stimulation in each unit pair. These indicate that correlations in the contrast-evoked activity are random; however, note the central depression at $t=0 \pm 10 \mathrm{msec}$ in $B$, reflecting the general reduction in levels of coincident activity resulting from visual stimulation in the strobe (see Table 1). Other conventions are as in Figure 2 insets.

To determine the effects of contrast-evoked firing on the relative levels of correlated and anti-correlated activity, which might provide a basis for distinguishing corresponding from noncorresponding tectal locations, we calculated coincidence indices for the period of stimulation and compared them with those for preceding periods of stable strobe entrainment. As shown in Table 1, these comparisons revealed that during visual stimulation the $C I_{10}$ was generally reduced, and by a similar degree, at both corresponding and noncorresponding sites. These findings strongly suggest that the additional firing induced by visual contrast produces an equivalent net loss in the probability of coincident activity at all tectal locations. The explanation for this rests with the temporal profile of the contrast-evoked RGC firing, which occurred sporadically over a long $(500 \mathrm{msec})$ period after each strobe flash, rather than in synchrony with elements of the entrained response.

\section{Effects of strobe rearing on binocular map development and plasticity}

Organizational features of the maps formed by the retinotectal and crossed isthmotectal (intertectal) projections were examined in 41 normal and 48 strobe-reared frogs.

\section{The topography of the retinotectal map is normal in strobe- reared frogs but may lack detailed precision}

The topographic order of the retinotectal projection in animals strobe-reared from embryonic stage 35/36 (see Figs. 6, 8) was indistinguishable from normal; stepwise microelectrode penetrations along the rostrocaudal or mediolateral tectal axes yielded similar nasotemporal or superoinferior progressions in RF posi- tion through the contralateral eye in both groups of frog. These features of normality after strobe rearing were shared by all three classes of RGC projecting to the tectum, as was their relative depth of termination within the superficial neuropil. In 89 penetrations made into the tectum of these animals $(n=14)$ in which two or three classifiable unit types were encountered, a complete sustained-event-dimmer sequence was obtained from superficial to deep in 31, and combinations of two unit classes in the same appropriate sequence were obtained in the remainder: that is, a sustained unit first and an event $(n=38)$ or a dimmer unit deeper down $(n=5)$ or just an event-dimmer $(n=15)$ combination. Similar proportions of classifiable unit types and sequences were recorded in 65 penetrations in control $(n=10)$ animals $\left(\chi^{2}=8\right.$; df $=7 ; p>0.3)$. In addition, as indicated in Figure 6, RFs of the different units encountered in any given penetration were, in large part, overlapping in space, especially in recordings from central tectum in which such penetrations should be near perpendicular to its surface. The scatter in the RF centers of different unit classes mapped sequentially at such central tectal sites was also comparable in strobe-reared (mean $\left.=6.0 \pm 3.0^{\circ}, \mathrm{SD} ; n=66\right)$ and normally reared frogs (mean $=5.5 \pm 2.7^{\circ}, \mathrm{SD} ; n=57$; Student's $t$ test, $p>0.4$ ). These results indicate that all three RGC classes in strobe-reared Xenopus are able to deploy their arbors with appropriate topographic order in the opposite tectum, both across its surface and in depth.

In these recordings the response fields of the multiunits that were plotted were typically $20-40^{\circ}$ in diameter (Fig. 6), irrespective of rearing conditions. However, to obtain a more accurate 


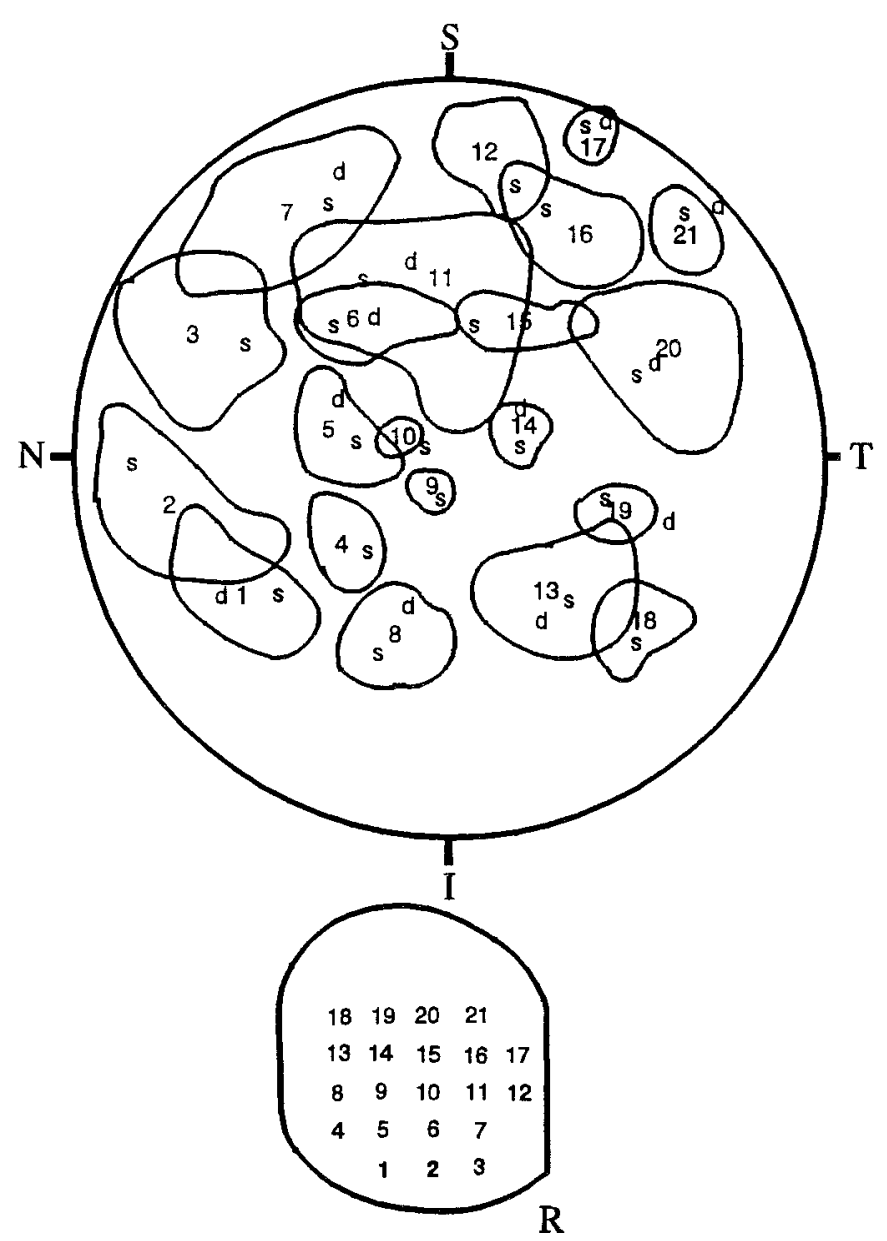

Figure 6. The retinotectal projection in a strobe-reared frog. The bottom diagram shows the outline of the right tectal lobe traced from a photograph of its dorsal surface, with the positions of microelectrode penetrations shown by numbers in the grid array. $R$, Rostral (medial is to the right). The large circle derives from the polar coordinate chart representing the hemispheric mapping perimeter, which closely approximates the visual field of the animal's left eye. The optic axis of this eye was centered on the origin of the perimeter. $N, T, S, I$, Nasal, temporal, superior, and inferior aspects of its visual field. In the chart representation, minimum response fields of single or multiunit event-type RGC projections recorded at each numbered tectal position are shown in outline and are marked by the corresponding number situated at or close to the RF center. At each tectal position sustained- and/or dimmer-type RGC projections with overlapping response fields also were mapped more superficially or at deeper locations, respectively, in the same penetration; $s$ and $d$ indicate the RF centers of these respective unit types. Note that the apparent enlargement of event-class response fields from center to periphery in the chart arises from the polar transformation of visual coordinates that were used and not from a genuine increase in RF size with eccentricity.

index of this aspect of the mapping fidelity, RF sizes in the retinotectal projection were measured by quantitative methods. Single-unit (class III) RF diameters were identical in the two groups of frog, averaging $19^{\circ}$ in both nasotemporal and superoinferior dimensions ( $n=10$ /group). MURF sizes, measured for each of the three RGC classes, are presented in Table 2. Illustrative three-dimensional matrix plots of the data that were obtained are shown in Figure 7. The average MURF diameters and their areas increased significantly with depth in both groups of frog (i.e., sustained $<$ event $<$ dimmer; Student's $t$ tests, $p<$ $0.05)$, but all equivalent dimensions were larger in the strobereared animals $(n=10)$ than in the controls $(n=12)$. The

\begin{tabular}{|c|c|c|c|}
\hline RGC class & MURF dimensions & Normal frogs & Strobe-reared \\
\hline \multirow[t]{3}{*}{ Sustained } & Nasotemporal & $23.0 \pm 4.9^{\circ}$ & $27.2 \pm 4.1^{\circ *}$ \\
\hline & Superoinferior & $19.0 \pm 2.4^{\circ}$ & $21.5 \pm 3.5^{\circ * *}$ \\
\hline & Area $\left(\right.$ degrees $\left.{ }^{2}\right)$ & $\begin{array}{l}345 \pm 105 \\
(n=11)\end{array}$ & $\begin{array}{l}484 \pm 116^{\text {**** }} \\
(n=19)\end{array}$ \\
\hline \multirow[t]{3}{*}{ Event } & Nasotemporal & $28.4 \pm 5.9^{\circ}$ & $32.2 \pm 6.5^{\circ *}$ \\
\hline & Superoinferior & $24.1 \pm 4.4$ & $24.6 \pm 5.7^{\circ}$ \\
\hline & Area $\left(\right.$ degrees $\left.{ }^{2}\right)$ & $\begin{array}{l}544 \pm 175 \\
(n=38)\end{array}$ & $\begin{array}{l}634 \pm 163^{*} \\
(n=33)\end{array}$ \\
\hline \multirow[t]{3}{*}{ Dimmer } & Nasotemporal & $31.8 \pm 5.6^{\circ}$ & $35.7 \pm 6.0^{\circ}$ \\
\hline & Superoinferior & $27.2 \pm 3.5^{\circ}$ & $28.3 \pm 3.0^{\circ}$ \\
\hline & Area $\left(\right.$ degrees $\left.{ }^{2}\right)$ & $\begin{array}{l}693 \pm 149 \\
(n=12)\end{array}$ & $\begin{array}{l}829 \pm 166 \\
(n=9)\end{array}$ \\
\hline
\end{tabular}

$t$ test, $p<0.05^{*} ; p<0.01^{* *} ; p<0.005^{* * *}$.

increases were statistically significant for sustained multiunits and for some of the event MURF dimensions.

Probing these differences further, it was evident from the matrix plots that the MURF profiles fell into two categories: those possessing a single, central peak of maximal activation (Fig. 7 $A, B$ ) and others possessing two or more regions of peak activity (Fig. 7C,D). This latter category of multiunit response could imply that the RGCs contributing to it had terminal arbors of normal size but cell bodies that were spatially separated on the retina, rather than immediate neighbors, and might be an expected trait of strobe-induced disorder in the retinotectal map (Cook and Rankin, 1986; Cook, 1987). Such responses were, however, recorded with similar frequency in the normal $(10$ of $61 ; 16 \%)$ and strobe-reared animals (14 of $61 ; 23 \%)$. We believe, therefore, that the consistent trend toward MURF enlargement across RGC classes after strobe rearing more likely reflects a general increase in retinal arbor size, so that our sampling was obtained from a more diff use set of active terminal branches. This interpretation is consistent with recent findings that retinal MURFs and arbor sizes are enlarged in the tectum of goldfish reared under a mixed strobe/ dark cycle (Schmidt and Buzzard, 1993).

\section{The topographic order and alignment of the crossed} isthmotectal map is disrupted in strobe-reared frogs

In 18 strobe-reared frogs the binocular inputs to one or both tectal lobes were mapped in sufficient detail to evaluate the order and alignment of the crossed isthmotectal projection. Two classes of result were obtained. In 10 animals the ipsilateral map or maps appeared completely normal, displaying good topographic order and spatial alignment with the map from the contralateral eye on the same tectal lobe. In the other frogs, an example of which is shown in Figure 8, the ipsilateral map or maps displayed abnormal features reminiscent of dark-reared Xenopus (Keating and Kennard, 1987; Grant and Keating, 1989b). Their overall topography showed some order, with sequences of electrode penetrations across the rostrocaudal or mediolateral axes of the tectum usually revealing appropriate temporonasal or superoinferior shifts in RF position. However, there were also signs of misalignment with the contralateral map, which were manifest at some recordings sites (e.g., 4, 7, and 27 in Fig. 8) by abnormally large spatial disparities between the RFs in the two eyes and manifest at others on the margins of the map (e.g., 1-3 and 31-33) by 
A

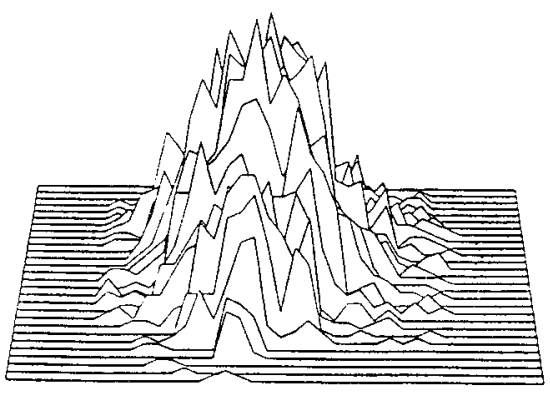

C

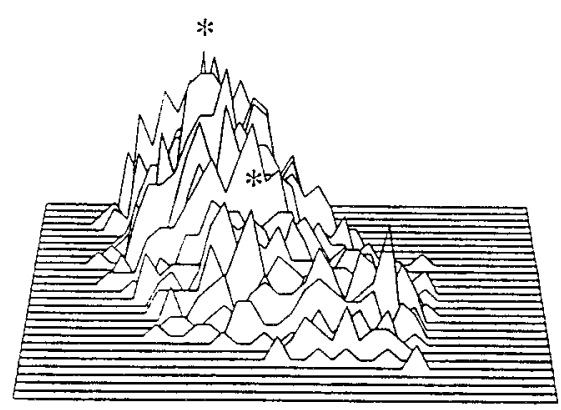

B

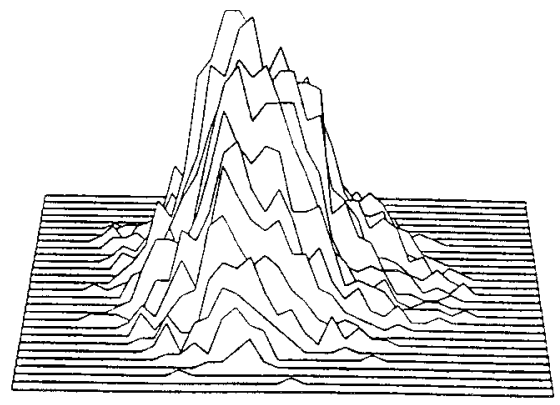

$\mathrm{D}$

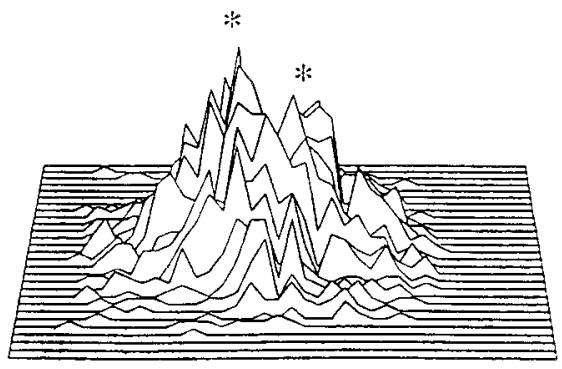

Figure 7. Three-dimensional representations of event-type MURFs recorded in $(A, C)$ normal and $(B, D)$ strobe-reared frogs. The $x$ - and $y$-axes correspond to $64.5^{\circ}$ of the nasotemporal and $34.5^{\circ}$ of the superoinferior visual field, equivalent to the area covered by the television monitor on which the MURFs were plotted. The $z$-axis represents the cumulative number of spikes recorded in each $1.5 \times$ $1.5^{\circ}$ pixel on the screen from three traverses in each orthogonal direction from which the MURF areas were measured. Asterisks $(C, D)$ denote double activation peaks.

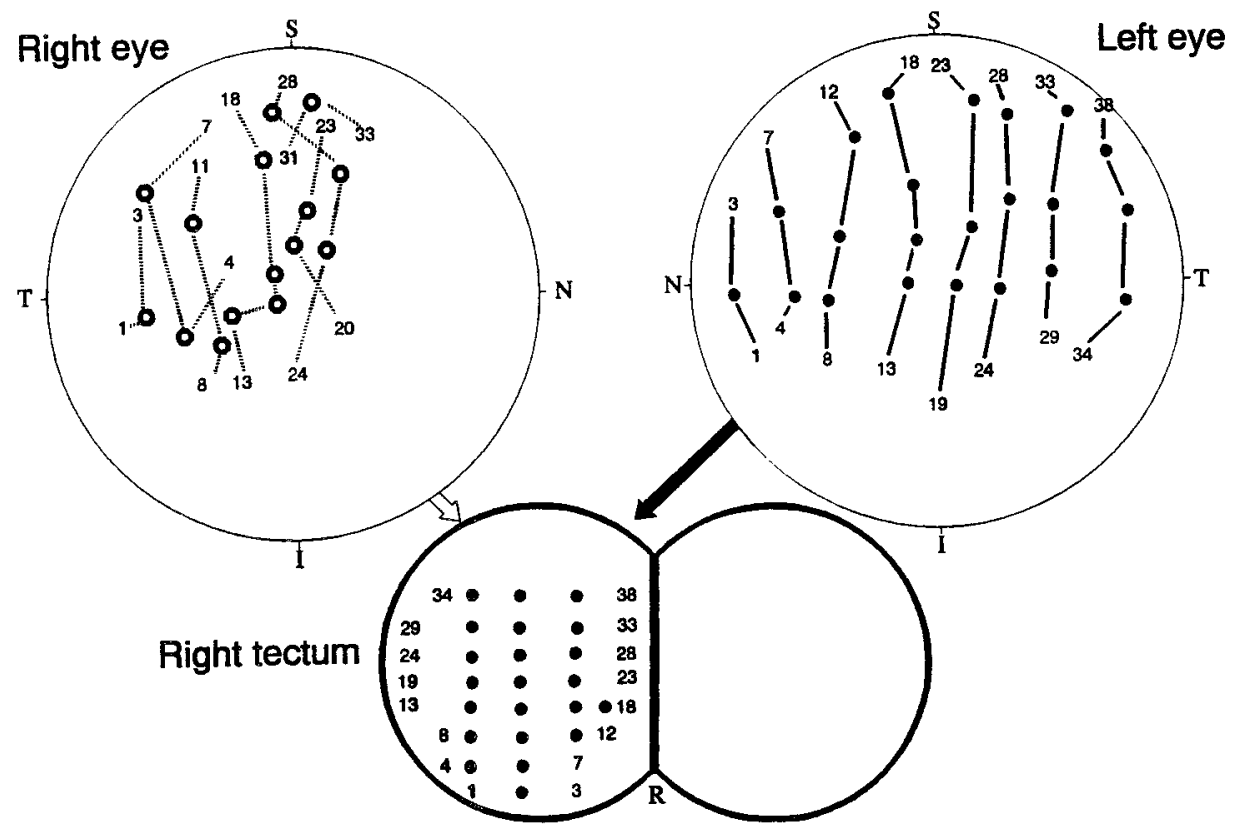

Figure 8. Binocular maps on the tectum of a strobe-reared frog. The dorsal outline of the optic tectum shows the recording positions (numbers and intermediate dots) on the right tectum in this mapping experiment. The corresponding numbers and intermediate dots in the chart representations indicate the minimum response field centers mapped through the tested eye. Filled symbols linked by solid lines represent RF centers recorded via the direct retinotectal projection from the contralateral eye (filled arrow); open symbols linked by discontinuous lines represent RF centers recorded via the crossed isthmotectal projection from the ipsilateral eye (open arrow). All other conventions, including left eye centering, are as in Figure 6 . The retinotectal map is organized normally, but the ipsilateral map shows topographic disorder and distortion and lacks proper alignment with the contralateral map at most recording positions.

systematic inward shifts in ipsilateral relative to contralateral RF positions, giving the maps a compressed appearance. At some of these recording sites (33 of 207; 16\%), ipsilateral multiunit response fields were almost double the normal size, ranging from 60 to $90^{\circ}$ in diameter.

Quantitative analyses of the strobe-reared ipsilateral maps were undertaken to establish more firmly the nature and severity of the abnormalities present and to better assess their similarity with those known to exist in Xenopus that were dark-reared to the same age. For these purposes, data from the strobe-reared frogs with apparently "unaffected" and "abnormal" maps were treated separately. The spatial alignment between the ipsilateral and contralateral maps, expressed by their mean absolute and nasotemporal binocular RF disparities, is given in Table 3. These latter disparities were grouped by mediolateral row of tectal recording sites and the mean values computed for each such row along the rostrocaudal axis. On our conventions, indications that the ipsilateral map is systematically compressed are revealed by large positive nasotemporal disparities rostrally and by large negative disparities caudally. There were no significant disparity differences between the control and the unaffected strobe-reared animals: absolute disparities averaged $\sim 10^{\circ}$, and nasotemporal disparities were within $\pm 5^{\circ}$ of zero for all rows, as previously reported in normal Xenopus at 1 year PM (Grant and Keating, 1989a). In the abnormal strobe-reared frogs, absolute disparities were significantly larger than normal, as were the positive and negative nasotemporal disparities in the most rostral and caudal tectal rows (outcomes that also were obtained after pooling these data with those from the "unaffected" animals). However, all of these disparity values were significantly smaller than in dark- 


\begin{tabular}{|c|c|c|c|c|c|c|c|c|c|}
\hline \multirow[b]{2}{*}{ Animals $(\mathrm{n}=)$} & \multirow{2}{*}{$\begin{array}{l}\text { Absolute disparity de- } \\
\text { grees (mean } \pm \mathrm{SD})\end{array}$} & \multicolumn{8}{|c|}{ Nasotemporal disparity by tectal row (degrees, mean \pm SD) } \\
\hline & & 1 & 2 & 3 & 4 & 5 & 6 & 7 & 8 \\
\hline $\begin{array}{l}\text { Normal } \\
\text { (7) }\end{array}$ & $\begin{array}{l}9.1 \pm 7.1 \\
(n=174)\end{array}$ & $\begin{array}{l}-1.3 \pm 6.4 \\
(n=15)\end{array}$ & $\begin{array}{l}-0.4 \pm 7.6 \\
(n=27)\end{array}$ & $\begin{array}{l}1.1 \pm 7.7 \\
(n=22)\end{array}$ & $\begin{array}{l}2.8 \pm 6.1 \\
(n=36)\end{array}$ & $\begin{array}{l}0.2 \pm 10.7 \\
(n=22)\end{array}$ & $\begin{array}{l}1.2 \pm 6.7 \\
(n=23)\end{array}$ & $\begin{array}{l}-0.3 \pm 6.1 \\
(n=15)\end{array}$ & $\begin{array}{l}4.8 \pm 5.9 \\
(n=14)\end{array}$ \\
\hline $\begin{array}{l}\text { Strobe-reared } \\
\text { "unaffected" (10) }\end{array}$ & $\begin{array}{l}9.0 \pm 3.7 \\
(n=185)\end{array}$ & $\begin{array}{l}2.8 \pm 9.0 \\
(n=18)\end{array}$ & $\begin{array}{l}1.4 \pm 7.7 \\
(n=28)\end{array}$ & $\begin{array}{l}0.8 \pm 5.3 \\
(n=19)\end{array}$ & $\begin{array}{l}2.6 \pm 6.8 \\
(n=48)\end{array}$ & $\begin{array}{l}1.4 \pm 7.7 \\
(n=19)\end{array}$ & $\begin{array}{l}1.5 \pm 7.9 \\
(n=37)\end{array}$ & $\begin{array}{l}-3.0 \pm 10.0 \\
(n=8)\end{array}$ & $\begin{array}{l}1.0 \pm 5.6 \\
(n=8)\end{array}$ \\
\hline $\begin{array}{l}\text { Strobe-reared } \\
\text { "abnormal" (8) }\end{array}$ & $\begin{array}{l}17.2 \pm 10.8^{* * *} \\
(n=207)\end{array}$ & $\begin{array}{l}10.5 \pm 13.8^{*} \\
(n=21)\end{array}$ & $\begin{array}{l}9.0 \pm 12.3^{* * *} \\
(n=36)\end{array}$ & $\begin{array}{l}3.4 \pm 10.9 \\
(n=20)\end{array}$ & $\begin{array}{l}4.5 \pm 12.4 \\
(n=34)\end{array}$ & $\begin{array}{l}5.3 \pm 19.1 \\
(n=13)\end{array}$ & $\begin{array}{l}-5.3 \pm 16.0 \\
(n=43)\end{array}$ & $\begin{array}{l}-8.8 \pm 19.3 \\
(n=12)\end{array}$ & $\begin{array}{l}-15.1 \pm 12.0^{* *} \\
(n=8)\end{array}$ \\
\hline $\begin{array}{l}\text { Dark-reared } \\
\text { (10) }\end{array}$ & $\begin{array}{l}26.5 \pm 19.3^{* * *} \\
(n=158)\end{array}$ & $\begin{array}{l}31.3 \pm 19.6^{*} \\
(n=8)\end{array}$ & $\begin{array}{l}15.6 \pm 18.3 \\
(n=22)\end{array}$ & $\begin{array}{l}14.0 \pm 20.8 \\
(n=38)\end{array}$ & $\begin{array}{l}4.8 \pm 24.7 \\
(n=42)\end{array}$ & $\begin{array}{l}-9.9 \pm 26.1 \\
(n=27)\end{array}$ & $\begin{array}{l}-16.5 \pm 26.8 \\
(n=15)\end{array}$ & $\begin{array}{l}-26.0 \pm 25.1 \\
(n=6)\end{array}$ & \\
\hline
\end{tabular}

$t$ test: ${ }^{*} p>0.005 ;{ }^{* *} p<0.001 ;{ }^{* *} p<0.0001$.

No ipsilateral responses were recorded from row 8 in dark-reared frogs, indicating that crossed isthmotectal arbors had not properly invaded this region.

reared frogs. Taken together, these results show that strobe rearing can lead to disorders in the crossed isthmotectal map, which are qualitatively similar to, but less severe than, those resulting from total visual deprivation.

\section{Only limited intertectal plasticity occurs after larval eye rotation in strobe-reared frogs}

The much larger scale reorienting of this map that usually follows early eye rotation also was affected by strobe rearing. In a control group of eye-rotated frogs reared under natural lighting conditions $(n=4)$, the binocular inputs mapped at one or both tectal lobes were found to be aligned spatially, despite the eye rotation present (which ranged from $60-180^{\circ}$ ). Absolute binocular RF disparities in these frogs (mean $\left.=8.7 \pm 4.8^{\circ}, \mathrm{SD} ; n=128\right)$ were no different from those in normal age-matched animals (Table 3 ), indicating that the reoriented map formed by crossed isthmotectal arbors in eye-rotated Xenopus allowed postoperative vision can be as accurate as a normally ordered one.

The results obtained from the strobe-reared frogs $(n=8)$ differed markedly from those of the controls; the ipsilateral maps showed both disorder and compression and no or very little plasticity. In five frogs with eye rotations of between 120 and $180^{\circ}$, the binocular inputs to one or both tecta were mapped at 89 recording sites and found to be completely misaligned by an amount equivalent to the degree and direction of the eye rotation present. An example is shown in Figure 9. This result implies that the crossed isthmotectal arbors in these frogs, although disordered, had maintained their normal orientation and is identical to the effects of dark rearing (Keating and Feldman, 1975) or of blocking tectal NMDA receptors (Scherer and Udin, 1989) after larval eye rotation in Xenopus.

The other three frogs, which had smaller eye rotations ranging from 60 to $120^{\circ}$, showed some evidence of intertectal plasticity. As illustrated in Figure 10, the binocular maps in these animals contained a mixture of predominantly misaligned with some aligned RFs in the two eyes. In most regions of the tectum the ipsilateral maps were disordered and out of register with the input from the contralateral eye by the degree of rotation present (mean disparity $=89.8 \pm 36.8^{\circ}, \mathrm{SD} ; n=83$ ), but in regions representing the visual field around the axis of the rotation, binocular RFs showed evidence of spatial correspondence. The mean disparities of these matching RFs $\left(15.2 \pm 7.2^{\circ}, \mathrm{SD} ; n=25\right)$ were significantly larger than in normal animals and in the control eye-rotated frogs (Student's $t$ tests; $p<0.0001)$ and no different from those in the "affected" (unrotated) strobe-reared group (Table 3). Nonetheless, such partial map alignment indicates that a cohort of crossed isthmotectal arbors had reorganized in these animals, almost compensating for the rotated visual input. A similar partial intertectal plasticity is known to occur during the initial process of map reorientation in Xenopus, but it has never been seen in eye-rotated animals reared in total darkness (Keating and Feldman, 1975; Grant and Keating, 1992; Keating and Grant, 1992).

\section{DISCUSSION}

The results show that (1) stroboscopic illumination induces high rates of entrained firing in Xenopus RGCs, masking any local correlations in their spontaneous discharges and synchronizing activity in the two eyes, and (2) in frogs reared under these conditions the precision, alignment, and plasticity of visual maps in the tectum are disrupted. We attribute these disruptions to strobe-induced levels of correlated afferent activation sufficient to obscure temporal differences between the pattern of activity at topographically appropriate and inappropriate synapses.

Strobe rearing was initiated mainly at embryonic hatching, when all retinal neuron classes are present in Xenopus, and just before the normal onset of photoreceptor function at stage 39/40 (Witkovsky et al., 1976). During the next 10-12 d (up to midlarval stage 49/50), RGC responses to visual stimulation, including transient light flashes, usually become increasingly reliable, coinciding with the emergence of distinct plexiform layers (Chung et al., 1975) and synaptic inputs from bipolar and amacrine cells onto discrete morphological classes of RGC resembling those of the adult retina (Fisher, 1976; Sakaguchi et al., 1984). This early period is also a key stage in the formation of the Xenopus retinotectal map. Previous studies have shown that retinal axons first form terminal arborizations in the tectum at stage 39 and that they undergo substantial refinements, especially along the rostrocaudal axis, until the appearance of well ordered topography at stage 49/50 (Gaze et al., 1974; Holt and Harris, 1983; O'Rourke and Fraser, 1986; Fujisawa, 1987). The arbor refinements have been visualized in situ and shown to be influenced by synaptic activity at NMDA receptors (O'Rourke et al., 1994). Whether the retinal origin of this activity is generated spontaneously, as occurs in other vertebrate classes while translaminar retinal inputs are being assembled (Maffei and Galli-Resta, 1990; Meister et al., 1991; Wong et al., 1993; Sernagor and Grzywacz, 1996), or is light-evoked remains unknown. Regardless, we doubt that strobe entrainment of RGC activity would have begun until these midlarval stages, when the retinal circuitry needed to drive their responses to light becomes fully established and the early map refinements are completed.

Major adjustments in retinotectal connectivity would be required during subsequent development, however, when activity is 


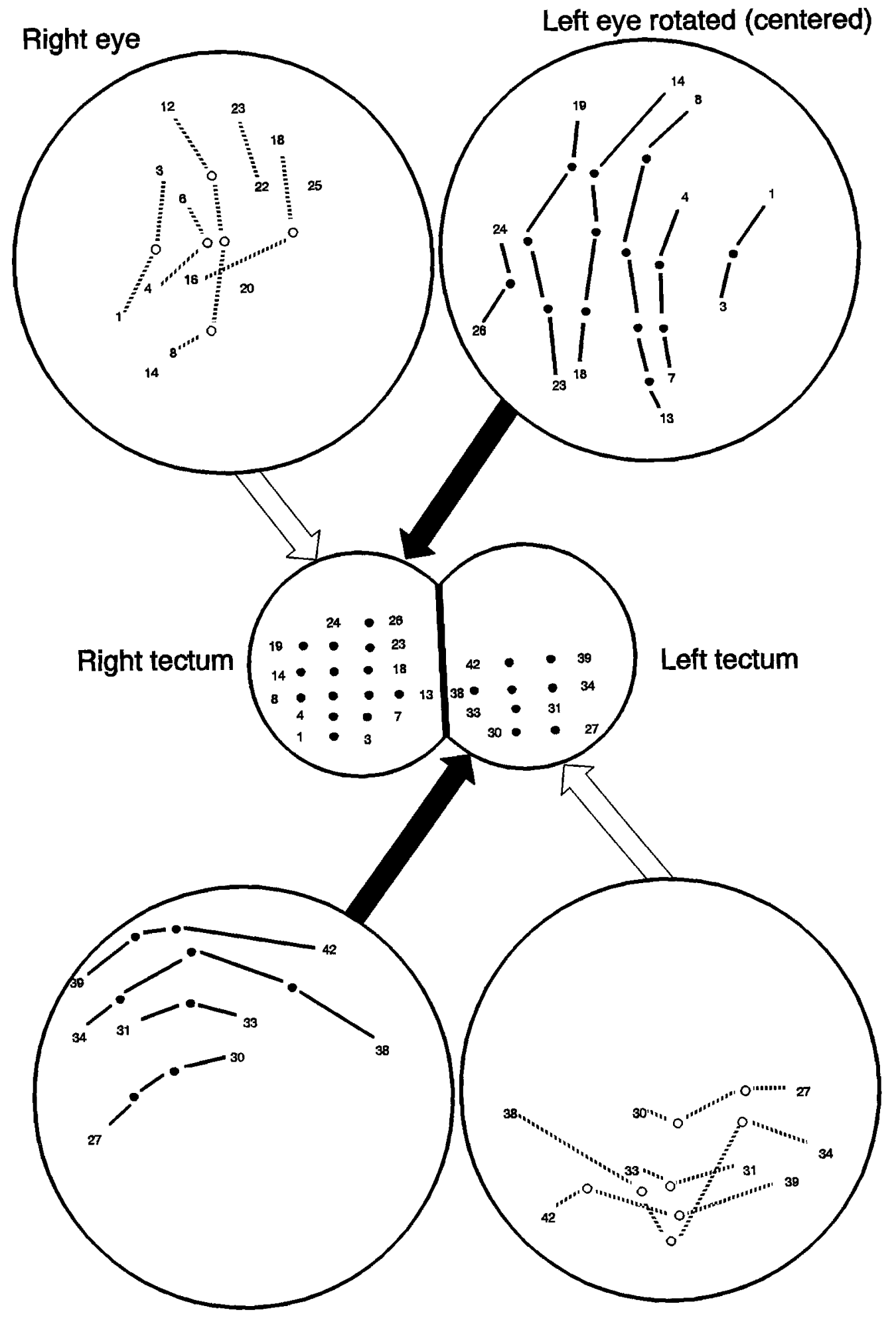

Figure 9. Binocular maps on the tectum of an eye-rotated, strobereared frog showing no evidence of intertectal plasticity. In this animal the left eye was rotated counterclockwise by $180^{\circ}$ at larval stage 56 . All conventions are as in Figure 8, except that the contralateral and ipsilateral maps on both tectal lobes are shown with the animal positioned so that its rotated eye is centered on the origin of the coordinate system. Both visual projections recorded through this operated eye are rotated $180^{\circ}$ counterclockwise, and both visual projections through the unoperated right eye are in a normal orientation. As a result, the binocular maps on each tectum are out of alignment by the degree and direction of the eye rotation present (e.g., compare RF positions $1-3$ in the two eyes). The ipsilateral maps also show signs of disorder and compression. synchronous under strobe conditions. New RGCs are added constantly to the retinal periphery throughout later larval and juvenile postmetamorphic life in Xenopus, unmatched by the pattern of tectal cell addition (Gaze et al., 1979; Grant and Keating, 1986b). To preserve the topography of the map during this period, resident retinal arbors are forced to shift in an orderly manner across the tectum, changing postsynaptic partners as they go. It is also in this period that arbors belonging to the different
RGC classes normally become sorted into distinct strata of the superficial tectum (Chung et al., 1975). The lack of effect of correlating activity on either the topography or the stratification of RGC class-specific projections strongly suggests that the underlying shifts in arbor position are achieved in Xenopus by activity-independent mechanisms, such as graded molecular affinities and selective adhesion in the target (see Sanes, 1993; Yamagata et al., 1995). This conclusion accords with reports that 
Figure 10. Binocular maps on the tectum of an eye-rotated, strobe-reared frog showing partial intertectal plasticity. All conventions are as in Figures 8 and 9. In this animal the left eye was rotated at larval stage 56 . For the most part, the binocular maps on each tectum are out of alignment by the degree and direction of the eye rotation present (equaling $120^{\circ}$ counterclockwise) at the time of recording. However, a component of each of the two ipsilateral maps arising from the central portion of the chart representation of the visual field (outlined) and recorded from a restricted portion of each tectal lobe (outlined) is rotated by $120^{\circ}$ counterclockwise in approximate spatial alignment with the corresponding RFs recorded through the contralateral eye (also outlined) at the same tectal positions. This implies that some arbors in the crossed isthmotectal projections of this animal had reorganized to compensate for the eye rotation. Note that at all five recording sites in the left tectum at which rotated RF positions were plotted through the ipsilateral eye (e.g., 57"), a second RF was also present in a normally oriented position (e.g., 57') within the more disordered and compressed part of its map. Such dual fields are common during the early postmetamorphic phase of eye rotation-induced map plasticity in Xenopus and indicate the coexistence of altered and normal arbors at the same tectal site (Grant and Keating, 1992).

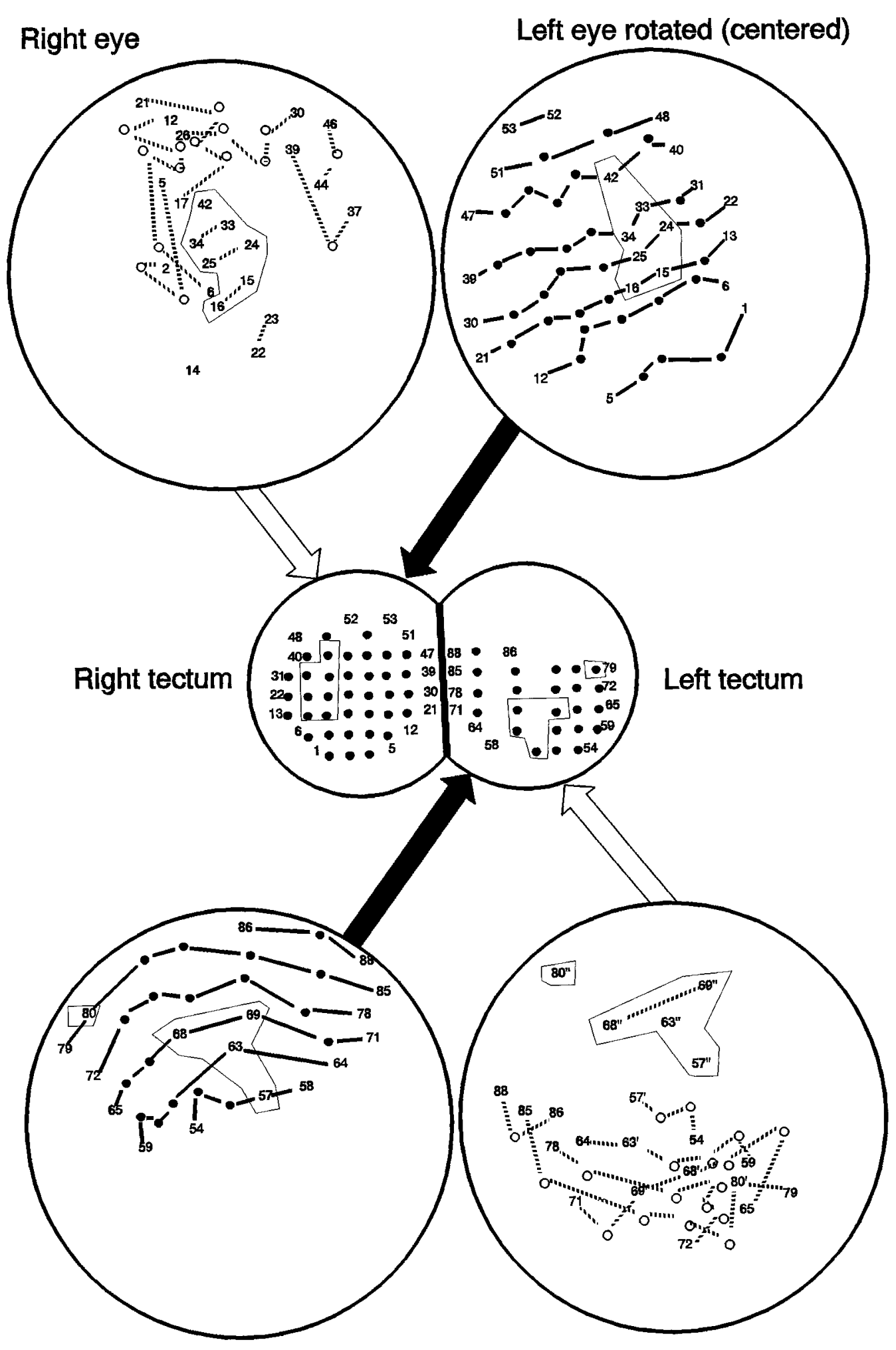

correct retinotectal arbor position, including lamination by RGC type, can be established independently of patterned activity in other amphibia (Harris, 1980) and in teleost fish (Stuermer et al., 1990; Schmidt and Buzzard, 1993); it also is in accord with the specific finding of Fraser et al. (1984) that brief application of neural cell adhesion molecule antibodies to early juvenile Xenopus tectum distorts the existing retinal map and almost doubles its MURF sizes.
A small, but consistent, increase in MURF sizes was also present after synchronizing RGC activity under strobe conditions. As in other frogs and in goldfish, Xenopus RGC arbors continue remodeling as they shift across the tectum, retracting older branches and synaptic contacts while extending new ones that are necessary to preserve their detailed point-to-point maps (Constantine-Paton et al., 1983; Easter and Stuermer, 1984; Fujisawa, 1987). The implication that these arbors are enlarged after 
strobe rearing suggests that the proper elimination of older branches and synapses may be repressed when their activity is highly correlated with that of more topographically appropriate arbors converging on the same tectal neurons. Such a temporary stabilization of coactive, although inappropriate, synapses supports the hypothesis that associative reinforcements of coactive retinal afferents normally contribute to maintaining their mapping precision (Cline and Constantine-Paton, 1989, 1990; Schmidt and Buzzard, 1993).

We can be confident that strobe-induced activity correlations were present throughout the development of the ipsilateral map. Crossed isthmotectal axons normally invade the Xenopus tectum after stage 50 and only form terminal arborizations at later metamorphic stages (Udin, 1989), coinciding with the appearance of visually driven, topographically organized ipsilateral units (Grant and Keating, 1989a). During subsequent postmetamorphic development in both normal and eye-rotated frogs, crossed isthmotectal arbors shift their position under the influence of visually evoked activity (Grant and Keating, 1986a, 1989a,b, 1992). These shifts are protracted, serving to maintain the topography of the map and match its RFs to corresponding retinal inputs in normal animals in which eye positions are changing continuously or to reacquire such spatial correspondence after eye rotation. In normal animals this process probably is accomplished by systematic remodeling of existing arbor structures, whereas eye rotation demands radical alterations in their trajectory, apparently involving a random search strategy (Udin, 1983). Both processes, however, are thought to be mediated by common mechanisms involving associative reinforcements or the elimination of crossed isthmotectal connections on the basis of their temporal activity correlations with convergent retinal afferents that activate postsynaptic NMDA receptors (Scherer and Udin, 1989).

Strobe rearing led to defective ipsilateral maps, and it blocked their complete reorganization in eye-rotated animals. We conclude that both systematic and radical shifts in crossed isthmotectal arbor position were disrupted because they had difficulty in distinguishing between retinal coactivity at inappropriate versus appropriate sites for binocular convergence. Importantly, these defects have been shown to resemble those that follow visual deprivation during the same developmental period, although they are generally less severe and less consistent. There are two likely explanations for this. First, because ipsilateral units are capable of responding to $1 \mathrm{~Hz}$ strobe flashes, they probably are activated with a degree of synchrony in the rearing environment, and it is known that correlated visual activity between neighboring crossed isthmotectal arbors can preserve their mapping order even when mismatched with rotated retinal input (Grant and Keating, 1992; Keating and Grant, 1992). Second, visual contrasts in the strobe environment may have provided additional spatiotemporal information for some relatively minor or gradual reorganizations to occur, such as remodeling of the normal map, but not for the larger scale plasticity required to compensate fully for an eye rotation. The nature of the partial plasticity observed in some of the eye-rotated frogs supports this possibility. As we have noted before (Grant and Keating, 1992), because crossed isthmotectal arbor dimensions average $\sim 200 \mu \mathrm{m}$ (Udin, 1989), ipsilateral map reorganization in central tectum representing the axis of the rotated eye and in the opposite rostral tectum (Fig. 10) could be achieved by remodeling the existing arbor framework without the need for changes in trajectory.

Although we have no explanation for why this information apparently was used more by some normal and eye-rotated animals than by others, a more interesting question concerns its content. Analyses of contrast-evoked responses during established strobe entrainment showed that they reduced the relative level of synchronous activity at all tectal sites while increasing noncoincident activity over intervals of $\pm 500 \mathrm{msec}$, some of which presumably were translated into asynchronous activation of crossed isthmotectal synapses. By analogy with the limits of temporal coincidence (up to $50 \mathrm{msec}$ ) between the activity of paired inputs capable of inducing associative LTP in the adult hippocampus (Levy and Steward, 1983; Gustafsson and Wigstrom, 1986), these conditions would seem to be inadequate for reinforcing appropriate crossed isthmotectal synapses. Indeed, given the persistent associative depression of weaker inputs reported in these and other hippocampal studies after asynchronous (by $\geq 100 \mathrm{msec}$ ) afferent activations (Stanton and Sejnowski, 1989; Otani and Connor, 1995), they might favor their elimination.

The temporal constraints within which developmental processes of "coincidence detection" actually operate, however, are unknown, and so the possibility remains that afferent activity correlations over hundreds, rather than tens, of milliseconds are of considerable significance. In fact, this possibility is consistent with evidence that NMDA receptor-mediated synaptic currents are this prolonged during periods of structural synaptic plasticity in the developing visual system (Carmignoto and Vicini, 1992; Hestrin, 1992) and that binocular visual stimulation needs to be asynchronous by at least $500 \mathrm{msec}$ to induce ocular dominance shifts in kitten cortex (Blasdel and Pettigrew, 1979; Altmann et al., 1987). The present demonstration that the detailed temporal patterning of neural activity within and between the two eyes influences their synaptic connectivity adds urgency to future characterization of the coincidence sensitivity of developing visual neurons.

\section{REFERENCES}

Aertson AMHJ, Gerstein GL, Habib MK, Palm G (1989) Dynamics of neuronal firing correlation: modulation of "effective connectivity." J Neurophysiol 61:900-917.

Altmann L, Luhmann HJ, Greuel JM, Singer W (1987) Functional and neuronal binocularity in kittens raised with rapidly alternating monocular occlusion. J Neurophysiol 58:965-980.

Berman NEJ, Payne BR (1985) An exuberant retinocollicular pathway in Siamese kittens: effects of competition and abnormal activity on its maturation. Dev Brain Res 22:197-209.

Blasdel GG, Pettigrew JD (1979) Degree of interocular synchrony required for maintenance of binocularity in kitten's visual cortex. J Neurophysiol 42:1692-1710.

Carmignoto G, Vicini S (1992) Activity-dependent decrease in NMDA receptor responses during development of the visual cortex. Science 258:1007-1011.

Chung S-H, Stirling V, Gaze RM (1975) The structural and functional development of the retina in larval Xenopus. J Embryol Exp Morphol 33:915-940.

Cline HT, Constantine-Paton M (1989) NMDA receptor antagonists disrupt the retinotectal topographic map. Neuron 3:413-426.

Cline HT, Constantine-Paton M (1990) NMDA receptor agonist and antagonists alter retinal ganglion cell arbor structure in the developing frog retinotectal projection. J Neurosci 10:1197-1216.

Cline HT, Debski E, Constantine-Paton M (1987) NMDA receptor antagonist desegregates eye-specific stripes. Proc Natl Acad Sci USA $84: 4342-4345$.

Constantine-Paton M, Pitts EC, Reh TA (1983) The relationship between retinal axon ingrowth, terminal morphology, and terminal patterning in the optic tectum of the frog. J Comp Neurol 218:297-313.

Constantine-Paton M, Cline HT, Debski E (1990) Patterned activity, synaptic convergence, and the NMDA receptor in developing visual pathways. Annu Rev Neurosci 13:129-154.

Cook JE (1987) A sharp retinal image increases the topographic preci- 
sion of the goldfish retinotectal projection during optic nerve regeneration in stroboscopic light. Exp Brain Res 68:319-328.

Cook JE, Rankin ECC (1986) Impaired refinement of the regenerated retinotectal projection of the goldfish in stroboscopic light: a quantitative WGA-HRP study. Exp Brain Res 63:421-430.

Easter SS, Stuermer CAO (1984) An evaluation of the hypothesis of shifting terminals in goldfish optic tectum. J Neurosci 4:1052-1063.

Fisher LJ (1976) Synaptic arrays of the inner plexiform layer in the developing retina of Xenopus. Dev Biol 50:402-412.

Fraser SE, Murray BA, Chuong C-M, Edelman GM (1984) Alteration of the retinotectal map in Xenopus by antibodies to neural cell adhesion molecules. Proc Natl Acad Sci USA 81:4222-4226.

Fujisawa H (1987) Mode of growth of retinal axons within the tectum of Xenopus tadpoles, and implications for the ordered neuronal connections between the retina and tectum. J Comp Neurol 260:127-139.

Gaze RM, Keating MJ, Chung S-H (1974) The evolution of the retinotectal map during development in Xenopus. Proc R Soc Lond [Biol] 185:301-330.

Gaze RM, Keating MJ, Ostberg A, Chung S-H (1979) The relationship between retinal and tectal growth in larval Xenopus: implications for the development of the retinotectal projection. J Embryol Exp Morphol 53:103-143.

George SA, Marks W (1974) Optic nerve terminal arborizations in the frog: shape and orientation inferred from electrophysiological measurements. Exp Neurol 42:467-482.

Goodman CS, Shatz CJ (1993) Developmental mechanisms that generate precise patterns of neuronal connectivity. Cell 72:77-98.

Grant S, Keating MJ (1986a) Normal maturation involves systematic changes in binocular visual connections in Xenopus laevis. Nature 322:258-261.

Grant S, Keating MJ (1986b) Ocular migration and the metamorphic and postmetamorphic maturation of the retinotectal system in Xenopus laevis: an autoradiographic and morphometric study. J Embryol Exp Morphol 92:43-69.

Grant S, Keating MJ (1989a) Changing patterns of binocular visual connections in the intertectal system during development of the frog, Xenopus laevis. I. Normal maturational changes in response to changing binocular geometry. Exp Brain Res 75:99-116.

Grant S, Keating MJ (1989b) Changing patterns of binocular visual connections in the intertectal system during development of the frog, Xenopus laevis. II. Abnormalities following early visual deprivation. Exp Brain Res 75:117-132.

Grant S, Keating MJ (1992) Changing patterns of binocular visual connections in the intertectal system during development of the frog, Xenopus laevis. III. Modifications following early eye rotation. Exp Brain Res 89:383-396.

Grigonis AM, Murphy EH (1991) Organization of callosal connections in the visual cortex of the rabbit following neonatal enucleation, dark rearing, and strobe rearing. J Comp Neurol 312:561-572.

Gustafsson B, Wigstrom H (1986) Hippocampal long-lasting potentiation produced by pairing single volleys and brief conditioning tetani evoked in separate afferents. J Neurosci 6:1575-1582.

Harris WA (1980) The effects of eliminating impulse activity on the development of the retinotectal projection in salamanders. J Comp Neurol 194:303-317.

Hestrin S (1992) Developmental regulation of NMDA receptormediated synaptic currents at a central synapse. Nature 357:686-689.

Holt CE, Harris WA (1983) Order in the initial retinotectal map in Xenopus: a new technique for labeling growing nerve fibres. Nature 301:150-152.

Keating MJ, Feldman JD (1975) Visual deprivation and intertectal neuronal connections in Xenopus laevis. Proc $\mathrm{R}$ Soc Lond [Biol] 191:467-474.

Keating MJ, Grant S (1992) The critical period for experiencedependent plasticity in a system of binocular visual connections in Xenopus laevis: its temporal profile and relation to normal developmental requirements. Eur J Neurosci 4:27-36.

Keating MJ, Kennard C (1987) Visual experience and the maturation of the ipsilateral visuotectal projection in Xenopus laevis. Neuroscience 21:519-527.

Keating MJ, Grant S, Dawes EA, Nanchahal K (1986) Visual deprivation and the maturation of the retinotectal projection in Xenopus laevis. J Embryol Exp Morphol 91:101-115.

Levy WB, Steward O (1983) Temporal contiguity requirements for long- term associative potentiation/depression in the hippocampus. Neuroscience 8:791-797.

Maffei L, Galli-Resta L (1990) Correlation in the discharges of neighboring rat retinal ganglion cells during prenatal life. Proc Natl Acad Sci USA 87:2861-2864.

Maturana HR, Lettvin JY, McCulloch WS, Pitts WH (1960) Anatomy and physiology of vision in the frog (Rana pipiens). J Gen Physiol 43:129-171.

Meister M, Wong ROL, Baylor DA, Shatz CJ (1991) Synchronous bursts of action potentials in ganglion cells of the developing mammalian retina. Science 252:939-943.

Nieuwkoop PD, Faber J (1967) A normal table of Xenopus laevis (Daudin), 2nd Ed . Amsterdam: North-Holland.

O'Rourke NA, Fraser SE (1986) Dynamic aspects of retinotectal map formation revealed by a vital dye fiber-tracing technique. Dev Biol 114:265-276.

O'Rourke NA, Cline HT, Fraser SE (1994) Rapid remodeling of retinal arbors in the tectum with and without blockade of synaptic transmission. Neuron 12:921-934.

Otani S, Connor JA (1995) Long-term depression of naive synapses in adult hippocampus induced by asynchronous synaptic activity. J Neurophysiol 73:2596-2601.

Rauschecker JP (1991) Mechanisms of visual plasticity: Hebb synapses, NMDA receptors, and beyond. Physiol Rev 71:587-615.

Reh TA, Constantine-Paton M (1985) Eye-specific segregation requires neural activity in three-eyed Rana pipiens. J Neurosci 5:1132-1143.

Sakaguchi DS, Murphey RK, Hunt RK, Tompkins R (1984) The development of retinal ganglion cells in a tetraploid strain of Xenopus laevis: a morphological study utilizing intracellular dye injection. J Comp Neurol 224:231-251.

Sanes JR (1993) Topographic maps and molecular gradients. Curr Opin Neurobiol 3:67-74.

Scherer WJ, Udin SB (1989) $N$-methyl-D-aspartate antagonists prevent interaction of binocular maps in Xenopus tectum. J Neurosci 9:3837-3843.

Scherer WJ, Udin SB (1991) Latency and temporal overlap of visually elicited contralateral and ipsilateral firing in Xenopus tectum during and after the critical period. Dev Brain Res 58:129-132.

Schmidt JT, Buzzard M (1993) Activity-driven sharpening of the retinotectal projection in goldfish: development under stroboscopic illumination prevents sharpening. J Neurobiol 24:384-399.

Schmidt JT, Eisele LE (1985) Stroboscopic illumination and darkrearing block the sharpening of the regenerated retinotectal map in goldfish. Neuroscience 14:535-546.

Sernagor E, Grzywacz NM (1996) Influence of spontaneous activity and visual experience on developing retinal receptive fields. Curr Biol 6:1503-1508.

Stanton PK, Sejnowski TJ (1989) Associative long-term depression in the hippocampus induced by Hebbian covariance. Nature 339:215-218.

Stiles M, Tzanakou E, Michalak R, Unnikrishnan KP, Goyal P, Harth E (1985) Periodic and nonperiodic burst responses of frog (Rana pipiens) retinal ganglion cells. Exp Neurol 88:176-197.

Stuermer CAO, Rohrer B, Munz H (1990) Development of the retinotectal projection in zebrafish embryos under TTX-induced neural impulse blockade. J Neurosci 10:3615-3626.

Udin SB (1983) Abnormal visual input leads to development of abnormal axon trajectories in frogs. Nature 301:336-338.

Udin SB (1989) Development of the nucleus isthmi in Xenopus. II. Branching patterns of contralaterally projecting isthmotectal axons during maturation of binocular maps. Vis Neurosci 2:153-163.

Udin SB, Fawcett JW (1988) Formation of topographic maps. Annu Rev Neurosci 11:289-327.

Udin SB, Keating MJ (1981) Plasticity in a central nervous pathway in Xenopus: anatomical changes in the isthmotectal projection after larval eye rotation. J Comp Neurol 203:575-594.

Witkovsky P, Gallin E, Hollyfield JG, Ripps H, Bridges CDB (1976) Photoreceptor thresholds and visual pigment levels in normal and vitamin A-deprived Xenopus tadpoles. J Neurophysiol 39:1272-1287.

Wong ROL, Meister M, Shatz CJ (1993) Transient period of correlated bursting activity during development of the mammalian retina. Neuron 11:923-938.

Yamagata M, Herman J-P, Sanes JR (1995) Lamina-specific expression of adhesion molecules in developing chick optic tectum. J Neurosci $15: 4556-4571$. 